\title{
La théologie au service du bon-ententisme à l'Université d'Ottawa : le père oblat Georges Simard (1878-1956), ou comment un groulxiste devient loyaliste
}

\section{Michel Bock}

Volume 11, 2016

URI : https://id.erudit.org/iderudit/1039287ar

DOI : https://doi.org/10.7202/1039287ar

Aller au sommaire du numéro

Éditeur(s)

Société Charlevoix

Presses de l’Université d’Ottawa

ISSN

1203-4371 (imprimé)

2371-6878 (numérique)

Découvrir la revue

Citer cet article

Bock, M. (2016). La théologie au service du bon-ententisme à l'Université d'Ottawa : le père oblat Georges Simard (1878-1956), ou comment un groulxiste devient loyaliste. Cahiers Charlevoix, 11, 213-260.

https://doi.org/10.7202/1039287ar
Résumé de l'article

Cet article propose une analyse de la pensée politique du père oblat Georges Simard (1878-1956), théologien et professeur à l'Université d'Ottawa pendant la première moitié du $\mathrm{XX}^{\mathrm{e}}$ siècle. Rattaché, à l'origine, à la faction nationaliste intransigeante des oblats canadiens-français, le père Simard changea son fusil d'épaule pour épouser d'abord le « bon-ententisme ", puis le loyalisme, après que Rome fut intervenue pour condamner le nationalisme catholique à la fois en Ontario français, dans le contexte de la crise du Règlement 17, et en Europe. À partir des années 1930, Simard mobilisa la théologie augustinienne pour justifier la cohabitation entre franco-catholiques et irlando-catholiques au sein de l'Université d'Ottawa, qu'il avait pourtant présentée, au début du siècle, comme l'université nationale des Canadiens français en Ontario. Cette nouvelle posture théologico-politique le conduisit aussi à combattre les intellectuels « séparatistes » qui s'étaient multipliés au Québec à la faveur de la crise économique et à appuyer sans réserve l'effort de guerre du Canada et de l'Empire britannique, dans lequel il voyait une " croisade " providentielle contre le nazisme et le communisme. L'étude de la trajectoire intellectuelle du père Simard fournit à l'historien des idées une clé précieuse pour mieux comprendre la transformation d'une partie du champ intellectuel de l'Ontario français dans le contexte de l'entre deux-guerres, ainsi que les origines religieuses du bilinguisme institutionnel au chapitre de son enseignement supérieur. 
La théologie au service du bon-ententisme à l'Université d'Ottawa : le père oblat Georges Simard (1878-1956), ou comment un groulxiste devient loyaliste

\author{
MicHEL BOCK \\ Chaire de recherche sur l'histoire \\ de la francophonie canadienne \\ Université d'Ottawa
}




\section{SOMMAIRE}

I - Du groulxisme au bon-ententisme 221

II - À l'assaut du « séparatisme » : la théologie et la philosophie politique du père Simard

III - Le passage au loyalisme et le débat Simard-Laurendeau

Conclusion

258 


\section{La théologie au service du bon-ententisme à l'Université d'Ottawa : le père oblat Georges Simard (1878-1956), ou comment un groulxiste devient loyaliste}

Au début des années 1930, l'abbé Lionel Groulx occupa brièvement une chaire d'histoire canadienne à l'Université d'Ottawa. Pendant deux ans, il y donna des cours prononcés d'abord à Montréal, « jusqu'au jour où l'Université oblate, en mal d'évoluer, jug[ea] bon de se donner un maître moins compromettant ${ }^{1}$ ", rapporte-t-il dans ses Mémoires. En 1934, on le remercia, en effet, de ses services, bien qu'on le fît de "façon gracieuse ", c'est-à-dire en lui conférant un diplôme honorifique en droit. Dans l'allocution, prononcée au moment de recevoir le grade, l'abbé Groulx, bon prince, vanta « la tâche d'une université telle que celle d'Ottawa qui ne form[ait] pas des "hommes abstraits", mais "des jeunes gens de race canadienne-française et d'une race encore plus haute : des catholiques" ». «[P]remier bastion de la vie française et catholique » en Ontario, renchérit-il, l'Université d'Ottawa avait la charge d'une mission qui engageait l'avenir de toute la nation canadienne-française.

L'abbé Groulx croyait-il vraiment ses propres paroles ? On peut se permettre d'en douter. Lorsqu'il rédigerait ses mémoires, à l'orée de la Révolution tranquille, c'est bel et bien au tournant des années 1930 que l'historien ferait remonter ce qu'il appellerait « la malheureuse évolution de l'Université oblate ${ }^{2}$ » qui, de « bastion » canadien-français qu'elle avait été - et jamais davantage que

1. Lionel Groulx, Mes Mémoires. Tome III : 1926-1939, Montréal, Fides, 1972, p. 263.

2. Ibid., p. 265. 
pendant la crise du Règlement $17^{3}$-, avait commencé à devenir, toujours à ses yeux, un lieu de compromission nationale, de partisannerie et de bon-ententisme. Groulx était déjà persuadé que, au lendemain de la crise scolaire, « une équipe de politiciens [s'était] substitu[ée] à l'équipe des lutteurs ${ }^{4} »$, non seulement au sein de l'élite canadienne-française d'Ottawa, mais aussi à l'intérieur même de la communauté oblate. Le diagnostic de l'abbé Groulx, qu'il faut recevoir, bien entendu, en tenant compte des impératifs idéologiques bien connus du personnage, n'en correspondait pas moins à quelque chose de tangible, soit la transformation du champ intellectuel de l'Ontario français au lendemain de la crise du Règlement 17 en 1927, laquelle aurait des conséquences non négligeables à court et à long terme. L'historien Robert Choquette a parlé d'une « révolution de palais ${ }^{5}$ » pour décrire la « purge » que subit l'élite laïque et cléricale d'Ottawa à ce moment. Au centre de cette opération de nettoyage se trouvait, entre autres, le père oblat Charles Charlebois, directeur-fondateur du journal Le Droit, chef du secrétariat de l'Association canadienne-française d'éducation d'Ontario (ACFÉo) et l'un des plus farouchement nationalistes, pour ne pas dire « groulxistes », des membres de la résistance au Règlement 17 . Le limogeage du père Charlebois était symptomatique du débat intellectuel et idéologique plus large qui se déroulait, au même moment, parmi les oblats d'Ottawa, dont certains semblaient vouloir prendre leurs distances par rapport aux thèses nationalistes qu'avait personnifiées leur confrère.

Choquette, à l'instar de Groulx lui-même, impute cette opération de nettoyage au retour des conservateurs au pouvoir en 1930, aussi bien à Ottawa qu'à Toronto. Le changement de régime politique aurait ainsi amené les bleus de la capitale à exiger quelques

3. Nous préférons la graphie en chiffres arabes de « Règlement 17 » à la graphie en chiffres romains, pourtant largement répandue, puisqu'elle correspond mieux à son appellation originale anglaise, "Circular of Instructions 17 ». Voir : crccf. uottawa.ca/passeport/IV/IVD1a/IVD1a01-1_b.html (page consultée le 3 juin 2016). p. 362 .

4. Lionel Groulx, Mes Mémoires. Tome I : 1878-1920, Montréal, Fides, 1970,

5. Voir Robert Choquette, La Foi gardienne de la langue en Ontario, 19001950, Montréal, Bellarmin, 1987, p. 210-213, 219-222. 
retours d'ascenseur après plusieurs années de vaches maigres, d'autant plus qu'un nombre élevé de membres de la résistance franco-ontarienne s'étaient acoquinés avec les libéraux. Sans nécessairement rejeter cette thèse, il nous semble qu'elle ne dit pas tout et qu'il y aurait lieu de situer la modification partielle du rapport au nationalisme canadien-français en milieu francoontarien dans son contexte intellectuel et religieux plus large. La crise du Règlement 17 contribua de manière substantielle, en effet, à transformer le champ intellectuel canadien-français en montrant les limites de la thèse de la langue, « gardienne » de la foi. Le Saint-Siège, en intervenant deux fois plutôt qu'une dans la crise scolaire (1916 et 1918), chercha à rétablir l'harmonie entre les militants franco-catholiques, qui fondaient leur action sur l'indissociabilité des questions religieuse et nationale, et leurs adversaires irlando-catholiques, qui craignaient, à l'inverse, que le nationalisme canadien-français ne vînt remettre en cause l'existence même du système scolaire catholique en Ontario ${ }^{6}$. En prenant le parti du camp irlandais et en condamnant, pendant les années 1920, le nationalisme « immodéré » et « outrancier », Rome contribua ainsi à déclencher une profonde remise en question du nationalisme canadien-français « orthodoxe », voire « groulxiste » et de l'union, que l'on estimait pourtant inviolable, de la langue et de la foi ${ }^{7}$. À Ottawa, où les oblats canadiensfrançais avaient joué un rôle de premier plan dans le mouvement de résistance au Règlement 17, l'appel à la modération lancé par le Vatican se fit entendre. Il n'en provoqua pas moins un débat substantiel entre les factions nationaliste et «bon-ententiste » de la communauté oblate, qui n'envisageraient pas tout à fait de la même manière l'avenir de la collectivité canadienne-française en Ontario, ni même à l'Université d'Ottawa...

6. Robert Choquette, Langue et religion : histoire des conflits anglo-français en Ontario, Ottawa, Presses de l'Université d'Ottawa, 1977, 268 p.

7. Michel Bock, « Le germe d'un divorce : la langue, la foi et le Règlement 17 », dans Michel Bock et François Charbonneau (dir.), Le Siècle du Règlement 17. Regards sur une crise scolaire et nationale, Sudbury, Éditions Prise de parole, 2015, p. $407-436$. 
En Ontario, donc, ce qu'on a appelé l' « Église-nation ${ }^{8}$ » canadienne-française possédait des limites à la fois intellectuelles et institutionnelles, résultats de la cohabitation à laquelle étaient astreints Franco-Ontariens et irlando-catholiques. L'étude du débat religieux sur la question nationale et linguistique en Ontario permettra non seulement de jauger la transformation qu'a connue le champ idéologique franco-ontarien pendant la période de l'entre-deux-guerres, elle apportera aussi un éclairage nouveau sur les origines intellectuelles du bilinguisme institutionnel en Ontario français, en particulier au niveau de l'enseignement supérieur. Il est étonnant que peu de chercheurs aient choisi d'exploiter cette veine, l'Église représentant, dans le contexte ontarien, l'un des premiers espaces institutionnels, répétons-le, que furent contraints de partager francophones et anglophones. Certes, la cohabitation occasionna d'innombrables conflits et presque autant de luttes pour le contrôle des structures paroissiales et épiscopales de la province, notamment dans l'Est et le Moyen-Nord - c'est d'ailleurs l'étude de cet aspect de la question qu'ont privilégiée la plupart des chercheurs'. Il n'en demeure pas moins que la cohabitation conduirait aussi certains intellectuels cléricaux de l'Ontario français à amorcer une réflexion substantielle sur les devoirs et responsabilités que la foi des Franco-Ontariens leur dictait en matière linguistique, nationale et politique.

À ce chapitre, le parcours intellectuel du père Georges Simard (1878-1956) nous parait particulièrement emblématique des tiraillements idéologiques que connurent les oblats de la capitale des années 1910 aux années 1940. Professeur de théologie, de philosophie et d'histoire ecclésiastique à l'Université d'Ottawa, Simard était aussi un conférencier et essayiste relativement proli-

8. Fernand Dumont, Genèse de la société québécoise, Montréal, Éditions du Boréal, 1996, 393 p.

9. Robert Choquette, op. cit.; Jack Cécillon, Prayers, Petitions, and Protests: The Catholic Church and the Ontario Schools Crisis in the Windsor Border Region, 1910-1928, Montréal et Kingston, McGill-Queen's University Press, 2013, 336 p. ; Michel Bock, "L'évêque Scollard et la question canadienne-française. Le diocèse de Sault-Sainte-Marie au cœur du conflit franco-irlandais (1904-1934) », Cahiers Charlevoix, $\mathrm{n}^{\circ} 10$ (2014), p. 13-63. 
fique qui prendrait la plume et la parole à maintes reprises au cours de sa carrière pour exprimer ses vues sur la question nationale et religieuse canadienne-française, entre autres thèmes. Son œuvre n'a cependant fait l'objet d'aucune étude approfondie, hormis la brochure - hautement élogieuse - que lui a consacrée l'historien ecclésiastique Émilien Lamirande, qui a choisi de mettre en valeur la grande admiration qu'il professait envers la théologie de saint $\operatorname{Augustin}^{10}$. Relevons aussi les quelques pages - non moins hagiographiques - que lui a données l'historien officiel et ancien recteur de l'Université d'Ottawa, l'oblat Roger Guindon, qui a vu en lui l'un des principaux bâtisseurs de la « coexistence féconde » qui se serait installée entre les composantes française et anglaise de l'université à partir des années $1930^{11}$. Guindon a d'ailleurs déploré que son confrère «n'a[it] pas reçu l'attention qu'il méritait » au Québec, silence qu'il imputait à l'hégémonie exercée, dans les milieux intellectuels, par les nationalistes québécois et leur aversion devant le canadianisme sous toutes ses formes ${ }^{12}$. À son avis, il s'agissait là d'une grave injustice, Simard méritant de prendre sa place dans le panthéon des principaux intellectuels du Canada français.

L'évaluation que fait Guindon de l'œuvre de Simard est pour le moins discutable, car la pensée de son confrère ne se démarquait pas particulièrement par sa profondeur analytique, comme nous le verrons dans ces pages. Son étude revêt toutefois une autre importance, car elle fournit une clé permettant de mieux saisir la transformation de l'échiquier idéologique de l'Ontario français pendant la période de l'entre-deux-guerres. Initialement rattaché à la faction nationaliste « intransigeante » de la communauté oblate,

10. Émilien Lamirande, Le Père Georges Simard, o.m.i. (1878-1956). Un disciple de saint Augustin à l'Université d'Ottawa, Ottawa, Éditions de l'Université d'Ottawa, 1981, 94 p. Voir aussi Une religieuse des Saints Noms de Jésus et de Marie, Bio-bibliographie du R.P. Georges Simard, o.m.i., Montréal, Éditions Beauchemin, 1939, 65 p.

11. Roger Guindon, Coexistence féconde. La dualité linguistique à l'Université d'Ottawa. Volume 3 : 1936-1965, Ottawa, Presses de 1'Université d'Ottawa, 1995, p. 1-14.

12. Ibid., p. 3 . 
le père Simard accepta même, pendant les années 1920, la charge de « chroniqueur attitré13 $»$ de la crise scolaire franco-ontarienne dans les pages de L'Action française de Montréal, fonction que lui avait confiée le directeur de la revue, Lionel Groulx, qui le comptait alors parmi ses proches. Graduellement, toutefois, les rapports entre les deux prêtres devaient se détériorer à la faveur de la mutation intellectuelle du père Simard, laquelle conduirait l'abbé Groulx à déplorer ce qu'il appellerait son « impérialisme » et à voir en lui l'un des principaux agents de l'évolution « malheureuse » de l'Université d'Ottawa - entendons, ici, sa conversion au bon-ententisme - au tournant des années 1930. Qualifier Simard d' " impérialiste » constitue peut-être une exagération (nous y reviendrons), mais il n'en demeure pas moins que notre oblat connaîtrait, à la suite des prises de position romaines sur la question du nationalisme, une évolution idéologique graduelle, mais substantielle. Disciple de saint Augustin, thomiste comme la majorité de ses confrères, Simard en viendrait à évaluer le débat sur la question nationale canadienne-française à l'aune de ses convictions théologiques, lesquelles le feraient passer du « groulxisme » au « bon-ententisme », à la critique du nationalisme et du « séparatisme » puis, à l'aube de la Deuxième Guerre mondiale, carrément au loyalisme, sinon à l'impérialisme ${ }^{14}$. Le père Simard représente ainsi un « cas » dont l'étude permettra de reconstruire une partie du débat religieux sur la question nationale et sur le bilinguisme institutionnel tel qu'il a pu avoir lieu parmi les oblats de l'Université d'Ottawa, à un moment où le champ intellectuel de l'Ontario français se trouvait en pleine reconfiguration ${ }^{15}$.

13. Lionel Groulx, Mes Mémoires. Tome II : 1920-1928, Montréal, Fides, 1971, p. 318.

14. Les sources qui ont servi à cette étude sont issues, pour l'essentiel, de l'œuvre publiée du père Simard, qui est l'auteur d'un nombre élevé d'articles et de brochures parus entre les années 1910 et les années 1940. Il a aussi produit plusieurs ouvrages, lesquels sont tous, sauf exception, des recueils de textes publiés antérieurement. Nous avons donc préféré nous référer, dans la mesure du possible, aux publications originales plutôt qu'à ces recueils.

15. Michel Bock, « Le germe d'un divorce », op. cit., p. 407-436. 


\section{I - DU GROULXISME AU BON-ENTENTISME}

Georges Simard est né en 1878 à Baie-Saint-Paul. Il fréquenta l'École normale de Québec avant d'entrer chez les oblats de Montréal en 1899 et de compléter ses études à l'Université d'Ottawa peu de temps après. En 1916, le père Simard devint professeur au Grand Séminaire et au Scolasticat Saint-Joseph d'Ottawa, avant de passer, cinq ans plus tard, à l'Université, où il enseignerait la philosophie et l'histoire de l'Église et dont il serait nommé doyen de la faculté de théologie en 1932. Simard aurait la particularité d'être un fervent admirateur de saint Augustin dans un contexte intellectuel et universitaire largement dominé par le thomisme. Le célèbre philosophe catholique français Étienne Gilson aurait d'ailleurs dit de lui qu'il était « le seul [C]anadien qui conn[ût] saint Augustin ${ }^{16} »$. Le père Simard comptait, de plus, parmi les fondateurs de la Société historique d'Ottawa, et aussi parmi ceux de la Revue de l'Université d'Ottawa, qui vit le jour en 1931 et à laquelle il prêterait régulièrement sa plume pendant de longues années.

L'arrivée de Simard à Ottawa au tournant du $\mathrm{xx}^{\mathrm{e}}$ siècle coïncida avec le déroulement d'une importante guerre intestine au sein même de la communauté oblate de la capitale, laquelle avait pour objet la vocation même de l'Université. Il faut savoir que le Collège de Bytown (l'ancêtre de l'Université d'Ottawa) avait été fondé en 1848 en tant qu'institution bilingue destinée à la fois aux Canadiens français et aux irlando-catholiques. Les oblats étaient présents depuis quelques mois seulement dans le modeste camp de bûcherons qu'était, à l'époque, la future capitale du Canada. Dans le contexte trouble des premières années de l'Union de 1841, on ne pouvait guère espérer mieux pour les Canadiens français qu'un collège bilingue, d'autant plus que la région comptait déjà une forte population irlando-catholique et que la missiologie des oblats, eux-mêmes de récents immigrants français, les conduisait à concevoir leur vocation en termes évangélisateurs et missionnaires plutôt qu'en termes « nationaux », culturels ou linguis-

16. Étienne Gilson, cité dans Émilien Lamirande, op. cit., p. 11. 
tiques ${ }^{17}$. La fin du XIX ${ }^{\mathrm{e}}$ siècle correspond, comme chacun le sait, à la montée à la fois du mouvement impérialiste britannique au Canada anglais et du mouvement nationaliste canadien-français. Elle correspond aussi à la croissance et à la transformation du Collège, qui reçut, en 1866, une charte universitaire civile avant d'obtenir, en 1889, une charte romaine, envers et contre les hauts cris que poussait l'archevêque de Québec, qui voulut protéger jalousement, mais en vain, l'exclusivité pontificale de l'Université Laval. Dans ce contexte, l'institution oblate prit rapidement la forme d'un laboratoire à l'intérieur duquel auraient libre cours les antagonismes nationalistes dont la vie publique canadienne portait alors la marque.

Les hostilités furent formellement déclenchées en 1874, lorsque le recteur de l'Université, le père Joseph-Henri Tabaret, accepta de larguer le bilinguisme de son institution, avec le consentement du conseil provincial des oblats, qui siégeait à Montréal. Sous prétexte que la population irlando-catholique risquait d'envoyer ses enfants au tout nouveau Ottawa Collegiate Institute, un collège anglo-protestant, sous prétexte aussi que la population canadienne-française de la capitale avait intérêt à perfectionner sa maîtrise de l'anglais, dans le contexte ontarien, l'Université d'Ottawa s'imposa alors un régime linguistique dans lequel l'ensemble de ses cours seraient donnés en anglais, hormis les cours de français et de religion destinés spécifiquement aux francophones. Ce régime d'unilinguisme anglais durerait vingt-sept ans, jusqu'en 1901. Au fil des décennies, la communauté oblate s'était très largement " canadianisée », de sorte que les Français et les Irlandais ne représentaient plus que des minorités en son sein. Au début du siècle, alors, les oblats canadiens-français, profitant de ce nouveau rapport de force, parvinrent à réintroduire le bilinguisme dans le programme d'étude de l'Université, ce qui

17. Tim Foran, « Transcending Language and Ethnicity : Oblates of Mary Immaculate and the Canonical Erection of the Diocese of Calgary, 1912-1916», Histoire sociale / Social History, vol. 41, no 82 (novembre 2008), p. 505-534 ; Roger Guindon, Coexistence difficile. La dualité linguistique à l'Université d'Ottawa. Volume 1 : 1848-1989, Ottawa, Presses de l'Université d'Ottawa, 1989, 210 p. 
eut l'heur de susciter la colère des plus intransigeants parmi leurs confrères irlandais, qui soutiendraient férocement que l'Université avait été fondée pour desservir principalement les catholiques de langue anglaise : n'avait-on pas souligné à grands traits le caractère essentiellement anglais de l'Université, quelques années plus tôt, pour justifier l'obtention d'une seconde charte pontificale au Canada, après que l'Université Laval eut obtenu la sienne en 1876 ? À la tête de la cabale irlandaise se trouvait l'ancien recteur de l'Université, James McGuckin, ainsi que son protégé, le vicerecteur, Michael Francis Fallon. Ce dernier fut rapidement exilé à Buffalo avant de rentrer au pays pour s'installer sur le trône épiscopal de London, dans le sud de la province, à partir duquel il deviendrait l'un des plus farouches défenseurs du Règlement 17, en 1912. Pendant ce temps, plusieurs oblats irlandais déserteraient l'Université, exigeraient la fondation à Ottawa d'une université anglo-catholique bien à eux, ainsi que la création d'une province oblate anglaise, autant de mesures devant leur permettre de s'affranchir de ce qu'ils considéraient comme la tutelle de leurs confrères canadiens-français, beaucoup plus nombreux.

C'est donc dans ce contexte mouvementé, très difficile pour les oblats, qu'arriva Georges Simard à Ottawa. Dans le conflit ethnolinguistique qui divisait à la fois son ordre et son université, le jeune religieux prit rapidement position. L'histoire de l'Université d'Ottawa compterait d'ailleurs parmi ses thèmes de prédilection pendant toute la durée de sa carrière, bien que son point de vue sur cette histoire serait appelé à évoluer de manière substantielle. En 1910, il publia son premier texte d'importance, une brochure d'une quarantaine de pages intitulée L'Université d'Ottawa. Histoire du passé. L'orientation de l'avenir. Précisons que l'étude parut peu de temps après la tenue du Congrès des Canadiens français de 1'Ontario, grande manifestation nationaliste qui avait attiré au centre-ville d'Ottawa 1200 délégués venus débattre de l'avenir national des Canadiens français dans la province au moment même où les orangistes et une partie du clergé irlando-catholique réclamaient la suppression des écoles 
« bilingues » ou « anglaises-françaises ». « [S]pectacle inoubliable », écrivit Simard à propos du Congrès, au cours duquel avait été exprimée la «volonté populaire » «de ne jamais cesser la revendication [des] droits [des Canadiens français] que le jour où justice intégrale leur aura été rendue $»^{18}$. On connaît la suite : le Congrès donna naissance à l'Association canadienne-française d'éducation d'Ontario (ACFÉo) et, un peu plus tard, au journal Le Droit (que dirigerait le père Charles Charlebois avec une fougue nationaliste peu commune). Le Règlement 17 serait adopté en 1912, déclenchant ainsi une crise linguistique et politique majeure qui allait durer quinze ans. Ce qui importait à Simard, toutefois, c'était de prouver l'invalidité de la thèse irlandaise selon laquelle l'Université d'Ottawa était d'abord au service des anglo-catholiques et ne devait offrir qu'un nombre limité de privilèges à leurs coreligionnaires canadiens-français. Mensonges !, affirma-t-il vigoureusement. Les fondateurs de l'Université avaient souhaité qu'elle fût « l'institution supérieure nationale » des Canadiens français, dont les intérêts linguistiques, culturels et religieux étaient gravement menacés en terre ontarienne. Mais la partie n'était pas gagnée, comme en témoignaient les agissements des confrères irlandais cherchant à revenir à l'unilinguisme de la fin du siècle dernier :

À notre grande tristesse, il faut bien l'avouer : le français banni pendant un temps de cette institution y est rentré de force et demeure toujours l'intrus contre lequel toutes les attaques possibles sont permises. La cause de cet état déplorable, ne serait-ce pas que notre peuple, celui qui surtout devrait bénéficier immédiatement des avantages de l'Université, en ignore la vraie nature. S'il la connaissait, il y a beau temps qu'il aurait mis à leur place les ravisseurs de leur patrimoine [les Irlandais]. Le problème de l'Université subsistera tant que la vérité ne sera pas devenue domaine public. ${ }^{19}$

18. [Georges Simard], L'Université d'Ottawa. Histoire du passé. L'orientation de l'avenir [brochure, 1910], p. 3.

19. Ibid., p. 40-41. 
Le père Simard se rallia donc au camp nationaliste et « charleboisien $»^{20}$. Le langage guerroyant qu'il utilisait pour désigner les Irlandais, les « ravisseurs » du patrimoine des Canadiens français, ne péchait pas par excès de tendresse et n'était pas sans rappeler celui qu'allait bientôt employer le père Charlebois au Droit. Simard, toujours aussi combatif, accepta de monter aux barricades à plusieurs reprises, pendant ces années, pour défendre la mission essentiellement canadienne-française et nationale de 1'Université d'Ottawa ${ }^{21}$. Son militantisme et ses convictions nationalistes attirèrent même l'attention de Lionel Groulx qui, depuis Montréal, voyait en lui « un excellent esprit et l'un des bons ouvriers du groupe d'Ottawa ${ }^{22} »$. C'est ainsi que Groulx, dès son accession à la direction de L'Action française, fin 1920, alla même jusqu'à lui offrir la fonction de chroniqueur attitré des affaires franco-ontariennes à la revue ${ }^{23}$. Simard accepta volontiers la responsabilité de la chronique et s'exécuta en publiant, sous le pseudonyme d'Aurèle Gauthier, une série d'articles sur le Règlement 17, « ce pelé, ce galeux, d'où nous vient tout le mal » et qui menaçait les «droits les plus sacrés et les plus chers ${ }^{24}$ » des Canadiens français, qui avaient pour eux l'histoire du pays, qu'avaient érigé deux peuples fondateurs égaux en droits, la Constitution, qui reconnaissait formellement ces droits, et, mieux encore, le droit naturel des peuples de demeurer fidèles à leur génie national, et dont l'auteur, la Providence, n'autorisait à cet égard aucune remise en cause. Tantôt, le père Simard prendrait à partie

20. Roger Guindon lui reprochera d'ailleurs son interprétation de l'histoire et de la mission de l'Université. Voir Roger Guindon, Coexistence difficile, op. cit., p. 176-182.

21. Georges Simard, L'Université d'Ottawa, Québec, Imprimerie de L'Événement, 1915, 40 p. ; Georges Simard, "L'Université d'Ottawa », La Bannière de Marie-Immaculée, 1923, p. 74-77 ; Georges Simard, «L'Université d'Ottawa et ses collèges affiliés », Almanach de la langue française, 1925, p. 102-103.

22. Lettre de Lionel Groulx à Édouard Montpetit, 12 mai 1930, Bibliothèque et Archives nationales du Québec (dorénavant BANQ), P1/A,2744.

23. Lettre de Georges Simard à Lionel Groulx, 11 novembre 1920, BANQ, $\mathrm{P} 1 / \mathrm{A}, 3453$

24. Aurèle Gauthier [pseudonyme de Georges Simard], " L'imbroglio scolaire ", L'Action française, 1921, p. 307. 
son confrère oblat Fallon, promu évêque de London, qui avait lancé « avec fracas la bombe qui [avait ouvert] officiellement la guerre $^{25} »$; tantôt il vilipenderait les orangistes qui ourdissaient de sourds complots, encore et toujours, pour contenir et combattre l'influence canadienne-française en Ontario et avec lesquels certains irlando-catholiques s'acoquinaient, sans comprendre que, si l'école catholique existait en Ontario, il fallait en remercier, au premier chef, les Canadiens français ${ }^{26}:$ «Non, n’eussent été les Canadiens français, nos amis [irlandais] ne jouiraient pas de leur autonomie religieuse et scolaire ; et la seule chance qu'ils ont de la conserver, c'est de faire queue derrière nous et de cacher leur petit nombre dans nos deux gros millions ${ }^{27}$. $\gg$ C'est aussi Simard que Groulx invita à recenser L'Appel de la race, roman qu'il avait lui-même écrit (sous le pseudonyme d'Alonié de Lestres) et dont l'action se déroule à Ottawa dans le contexte de la crise scolaire, mettant en scène un oblat fictif, le père Fabien, qui réveille le sens national du protagoniste, Jules de Lantagnac, largement anglicisé après plusieurs années de vie conjugale avec une Canadienne anglaise de la capitale. Le livre se retrouva rapidement au centre de plusieurs polémiques à la fois politiques et théologiques ${ }^{28}$, d'où la nécessité, du point de vue de Groulx, de le faire recenser non seulement par un Franco-Ontarien, mais par un FrancoOntarien aux idées claires et au jugement sûr. Simard accepta et, sans pseudonyme, cette fois, remercia l'auteur de «l'épaulement moral » qu'avait apporté L'Appel de la race, vanta la doctrine $\mathrm{du}$ « nationalisme intégral » qui lui servait de fondement, et se réjouit de ce qu'il venait partiellement combler l'absence d'une « littérature nationale supérieure » au Canada français, c'est-à-dire une littérature capable de proposer un « idéal » canadien-français "véritable » pouvant détourner la jeunesse de son absorption

25. Ibid., p. 306.

26. Ibid., p. 310-311.

27. Ibid., p. 311.

28. Michel Bock, Quand la nation débordait les frontières. Les minorités françaises dans la pensée de Lionel Groulx, Montréal, Hurtubise HMH, 2004, 456 p. 
dans la « masse hétérogène » des « adversaires, [d]es ennemis qui nous entourent $»^{29}$.

Le père Simard écrivit ces lignes en 1922. Par la suite, ses prises de position sur la question nationale se feraient moins agressives et de plus en plus modérées. Malheureusement, notre oblat ne détailla jamais explicitement les raisons qui s'étaient profilées derrière cette réorientation intellectuelle. Nous savons toutefois que le contexte intellectuel de l'Ontario français et du Canada français dans son ensemble devait connaître, à peu près au même moment, une mutation importante provoquée en partie par les prises de position de Rome sur la question du nationalisme, à commencer par sa double intervention dans la crise scolaire franco-ontarienne. Le Saint-Siège, qui s'était appliqué à rétablir l'unité de l'Église canadienne, en proie aux divisions provoquées par le conflit franco-irlandais, donna finalement raison au parti irlandais, qui soutenait que les agissements des nationalistes canadiens-français risquaient de mettre en péril l'existence même des écoles catholiques en Ontario, toutes langues confondues ${ }^{30}$. Le jugement du Saint-Siège se fondait essentiellement sur les rapports secrets qui lui avait fait parvenir son délégué apostolique au Canada, $M^{\text {gr }}$ Peregrin Stagni, qui avait catégoriquement rejeté la thèse nationaliste de la langue, " gardienne » de la foi, et qui avait suggéré qu'on mît hors d'état de nuire les principaux agitateurs nationalistes d'Ottawa dont, au premier chef, le père Charlebois. L'intervention du Saint-Siège sema la consternation non seulement parmi les nationalistes de la capitale fédérale, mais aussi parmi leurs amis de Montréal, dont l'abbé Groulx. Lorsque le pape mit le monde en garde, en 1922, contre le nationalisme " immodéré » et, quatre ans plus tard, contre le nationalisme « outrancier » de L'Action française de Charles Maurras à Paris,

29. Georges Simard, «Un épaulement moral », L’Action française, 1922, p. 215.

30. Michel Bock, «Le Vatican et l'Ontario français au moment du Règlement XVII », dans Martin Pâquet, Matteo Sanfilippo et Jean-Philippe Warren (dir.), Les Archives du Vatican. Pistes et défis pour la recherche au Québec et en Amérique française, Québec, Presses de l'Université Laval, 2013, p. 257-276. 
les nationalistes canadiens-français comprirent qu'il leur faudrait désormais surveiller de près leurs paroles et leurs gestes, même si leur doctrine avait somme toute peu en commun avec celle des maurrassiens, que Rome accusait d'avoir instrumentalisé l'Église et le catholicisme à des fins politiques et nationales ${ }^{31}$. À Ottawa, par exemple, l'ACFÉo abandonnerait largement la stratégie de la confrontation dans son combat contre le Règlement 17 pour y préférer celle de la modération et de la conciliation. C'est aussi à ce moment que l'on peut retracer l'évolution intellectuelle du père Simard.

Cette évolution était visible dans les pages de L'Action française de Montréal dès 1923, alors qu'il commit un texte, un autre, sur l'Université d'Ottawa, un texte dont le ton n'était déjà plus tout à fait le même. L'institution oblate, estimait-il maintenant, était d'abord et avant tout catholique, elle n'était donc plus, fallait-il en déduire, au service, principalement, des Canadiens français. Et le catholicisme

ordonne [...] à ceux qui le vivent, de se dévouer, à quelque nationalité qu'ils appartiennent, à la formation religieuse et ethnique des enfants dont ils ont la charge. Cette doctrine [...] a rendu aptes les éducateurs du collège universitaire d'Ottawa à l'accomplissement de leur tâche périlleuse, à savoir instruire et former côte à côte la jeunesse de deux peuples dans un siècle où le nationalisme, souvent mal compris, jette les unes contre les autres des races liées par le sang ou très bien faites pour s'entendre ${ }^{32}$.

Ce dernier mot n'était pas innocent, dans le contexte du début des années 1920. Le mouvement de la « bonne entente », qu'avait lancé une partie de l'élite canadienne-anglaise pendant la Grande Guerre afin de mousser l'appui à la conscription militaire au Québec, avait été fréquemment tourné en dérision par les nationalistes

31. Voir Michel Bock, « L'influence du maurrassisme au Canada français : retour sur le cas de Lionel Groulx », dans Olivier Dard (dir.), Charles Maurras et l'étranger. L'étranger et Charles Maurras, Berne, Éditions Peter Lang, 2009, p. 135-152.

32. Georges Simard, «L'Université d'Ottawa », L'Action française, 1923, p. 178-178. 
canadiens-français, qui y avaient vu une manœuvre destinée, à grands coups de discours et de banquets soporifiques, à endormir leur conscience nationale ${ }^{33}$. Or Simard se montrait à présent critique du nationalisme tout en offrant au lecteur, dans le même souffle, un plaidoyer pour la « bonne entente ». Plus loin, dans le même article, il mit en garde ses compatriotes contre la « poudre nationale », " poudre inévitable et dangereuse tout à la fois ${ }^{34}$ ", tout en défendant la nécessité « patriotique » d'enseigner l'anglais aux Franco-Ontariens, à défaut de quoi « ils n'occuper[aie]nt jamais, dans l'Ontario, de hautes positions sociales ${ }^{35}$. L'évolution intellectuelle de notre oblat paraissait substantielle, au point où on commence déjà à éprouver un peu de mal à le reconnaître... Il n'est sans doute pas inutile de relever qu'entre 1921 et 1923 , le père Simard publia six articles dans les pages de L'Action française, alors que de 1923 à 1928, il n'en fit plus paraître que deux. Le premier, intitulé «L'Ottawa intellectuel », lui donna l'occasion de prendre à partie François Hertel, nom de plume du jésuite Rodolphe Dubé, qui avait commis un texte dissertant sur les qualités intellectuelles et culturelles de Québec et de Montréal, mais en gardant le silence sur la capitale fédérale, dont il semblait à Simard qu'il fallait prendre la défense. Surtout, l'article lui fournit un autre prétexte pour prêcher la bonne entente entre coreligionnaires francophones et anglophones au sein de l'Église ontarienne et conspuer un certain nationalisme qui « jet[ait] les catholiques les uns contre les autres, divisant les diocèses, les familles religieuses et les paroisses », le même nationalisme qu'il voyait à l'œuvre, de surcroît, à l'Université d'Ottawa ${ }^{36}$.

C'est de ce dernier nationalisme, à base de racisme, que souffre d'une façon aigüe [sic] notre Église canadienne. Crise inévitable

33. Sur le mouvement de la « bonne entente », voir Robert Talbot, « Une réconciliation insaisissable : le mouvement de la bonne entente, 1916-1930», Mens. Revue d'histoire intellectuelle de l'Amérique française, vol. 8, $\mathrm{n}^{\circ} 1$ (automne 2007), p. 67-125. p. 181 .

34. Georges Simard, "L'Université d'Ottawa », L'Action française, 1923,

35. Ibid., p. 181-182.

36. Roger Guindon, Coexistence féconde, op. cit., p. 6. 
jusqu'à un certain point, vu la composition de notre peuple et les idées démocratiques déposées dans la société contemporaine par cet imbécile de Rousseau. [...] Unis, les catholiques ontariens, pour exercer leur zèle belliqueux, auraient assez de défendre leurs écoles contre les envahissements de l'Étatisme $[\text { sic }]^{37}$.

Contre le racisme, contre les Lumières, contre l'étatisme, le catholicisme devait plutôt s'ériger en rempart et faire l'unité des fidèles en leur rappelant, au final, que l'Église était la dépositaire de la seule autorité qui fût légitime, non pas celle des peuples, des nations ou des races, mais celle de la Providence. La dernière contribution de Simard à L'Action française - devenue canadiennefrançaise au lendemain de la condamnation pontificale qui frappa le mouvement maurrassien en 1926 - prit la forme d'un véritable panégyrique consacré au père Tabaret, recteur de l'Université d'Ottawa pendant vingt-sept ans au XIX ${ }^{\mathrm{e}}$ siècle et dont on s'apprêtait à souligner le centenaire de la naissance. Il s'agissait, rappelons-le, du même Tabaret qui avait introduit, en 1874, le régime unilingue anglais qui devait sévir dans l'institution oblate jusqu'en 1901 - et qu'avait vertement déploré Simard quelque quinze ans plus tôt. Sous sa plume devenue passablement lénifiante, il faut bien le reconnaître, Tabaret n'était pas le spoliateur des droits linguistiques des Canadiens français, mais « une âme élevée » qui avait voulu répondre « le mieux possible aux légitimes aspirations de la jeunesse catholique du Canada central, qu'elle appartînt à la langue française ou à l'agglomération anglo-saxonne ${ }^{38} \gg$. Du régime linguistique de 1874, toutefois, pas le moindre mot, silence que plusieurs de ses confrères demeurés plus fidèles aux idées nationalistes ne manquèrent pas de relever et de tourner en dérision... ${ }^{39}$

37. Armand Rochefort [pseudonyme de Georges Simard], « L'Ottawa intellectuel », L'Action française, avril 1927, p. 234-235.

38. Georges Simard, "Le Père Tabaret », L'Action française, avril 1928, p. $213-214$.

39. Roger Guindon, Coexistence menacée. La dualité linguistique à l'Université d'Ottawa. Volume 2 : 1898-1936, Ottawa, Presses de l'Université d'Ottawa, 1992, p. $120-121$. 
Si le père Simard comptait parmi ceux qui avaient choisi de suivre à la lettre les directives pontificales en s'appliquant à rétablir la concorde au sein de son ordre religieux, les oblats irlandais, pour leur part, n'avaient pas déposé les armes pour autant. Au contraire, ils déployèrent de nombreux efforts pour tenter de rompre avec leurs confrères canadiens-français, des efforts qui furent éventuellement couronnés de succès, du moins en partie. En 1926, ils obtinrent d'abord la création d'une province oblate autonome, la province St. Peter, qui les libéra de la tutelle du conseil provincial de Montréal. Puis, trois ans plus tard, après qu'ils eurent revendiqué une université anglo-catholique indépendante, Rome les autorisa à fonder un collège de langue anglaise, le collège St. Patrick. La nouvelle institution demeurerait toutefois affiliée à l'Université d'Ottawa, qui n'abandonnerait pas sa mission de bilinguisme pour autant, en dépit de la francisation substantielle que connut, par la suite, son corps étudiant. Ces événements coïncidèrent en grande partie avec le rectorat du père Uldéric Robert (1927-1930), recteur « séparatiste », pour emprunter à Roger Guindon, qu'avait placé à la tête de l'Université d'Ottawa le conseil provincial des oblats. Toujours selon Guindon, le conseil provincial, véritable repaire de nationalistes, avait tenté, depuis Montréal, un véritable coup de force dans le dessein de donner à l'Université une mission largement, sinon exclusivement canadienne-française et de faire échec, ce faisant, à l'influence irlandaise ${ }^{40}$. L'autonomisation des pères irlandais survint aussi, faut-il le rappeler, au lendemain de la crise du Règlement 17, précédant de peu le moment où la direction des oblats, pressée par le délégué apostolique, se résigna enfin à évincer le père Charlebois, l'un des principaux chefs des nationalistes d'Ottawa, d'abord en l'écartant de la direction du Droit et de l'AcFÉo, puis en l'exilant carrément à Saint-Agathe-des-Monts. Rappelons que c'est justement ce qu'avait recommandé dès 1915 le délégué apostolique de l'époque, Peregrin Stagni, dans ses rapports secrets sur la crise scolaire franco-ontarienne. Robert Choquette

40. Ibid., p. 119-135. 
a montré le rôle déterminant qu'a joué dans cette affaire le successeur du père Robert au rectorat de l'Université, le père Gilles Marchand, qui reprochait à Charlebois de ne pas s'être adapté « aux nouvelles conditions ${ }^{41}$ » du moment. Le chanoine Groulx, dans ses Mémoires, prétend toutefois que « [1] plus ardent à demander l'expulsion du [p]ère Charlebois [...] [avait été] le [p]ère Georges Simard » lui-même, son ancien collaborateur à L'Action française qui, depuis, se livr[ait] à une « [g]uerre sans pitié, menée à coups d'insinuations et d'accusations perfides, comme toute guerre fratricide », une « [g] uerre qui devait jeter les uns contre les autres d'anciens compagnons d'armes $»^{42}$. Il n'est pas facile de vérifier cette hypothèse, celle du rôle qu'a pu tenir Simard dans le limogeage de son confrère Charlebois. On sait toutefois que les distances qu'il avait prises par rapport à la cause nationaliste continuèrent de se creuser à partir de ce moment. Par exemple, dans une brochure publiée sur la question romaine en 1929, au lendemain de la conclusion des accords du Latran, il s'autorisa à faire de nombreux apartés pour réclamer que les Canadiens français cessent de se disputer avec leurs « frères » irlandais « au seuil des écoles et sur les parvis des temples », et que l'on cess[ât] aussi de craindre l'impérialisme anglo-saxon, dont la menace pâlissait devant celle que posait, en revanche, l'impérialisme économique, intellectuel et moral des États-Unis ${ }^{43}$. En 1931, c'est encore Simard qui rédigea l'article-manifeste de la toute nouvelle Revue de l'Université d'Ottawa, qui aurait pour mission, expliqua-t-il, de réfléchir à " [n]otre unité politique », à « la pacification de notre [É]glise » et « à la prospérité de nos classes ouvrières », de manière à placer l'institution oblate « au-dessus des luttes de races et de langues dont souffre de façon endémique la Capitale de notre cher Canada ${ }^{44}$. Le père Simard pouvait encore, en 1932,

41. Robert Choquette, La Foi gardienne de la langue en Ontario, op. cit., p. 197-205.

42. Lionel Groulx, Mes Mémoires. Tome I, op. cit., p. 361.

43. Georges Simard, La Question romaine, Ottawa, Université d'Ottawa, 1929, p. 26-27.

44. Georges Simard, «La Revue de l'Université d'Ottawa », Revue de l'Uni- 
faire l'éloge de l'œuvre historique de l'abbé Groulx, qu'il plaçait toujours « parmi les grands historiens, les bienfaiteurs de sa race et les prêtres les plus méritants du clergé catholique », mais le « nationalisme intégral ${ }^{45}$ » dont il avait encore pu se réclamer, quelque dix ans plus tôt, lui paraissait bel et bien révolu.

\section{II - À L'ASSAUT DU « SÉPARATISME » : LA THÉOlOGIE ET LA PHILO- SOPHIE POLITIQUe dU PÈRE SIMARD}

Deux ans plus tard, en 1933, le père Simard publiait dans la Revue de l'Université d'Ottawa un article qui devait marquer, dans son parcours intellectuel, un tournant décisif en contribuant à cristalliser une pensée en évolution depuis une dizaine d'années. Disciple de saint Augustin, comme nous l'avons mentionné ci-dessus, Simard puisa dans La Cité de Dieu de nombreux enseignements pour tenter de résoudre le problème de « La race et [de] la langue françaises dans l'Église du Canada ${ }^{46} »$. Mobilisant l'idée augustinienne voulant que la Cité de Dieu - l'Église - fût ouverte à tous les peuples et à toutes les langues, sans discrimination, qu'elle dût demeurer distincte, quoique liée, à la Cité terrestre, mais qu'elle disposât, en revanche, du droit de mettre la Cité terrestre au pas lorsque cette dernière outrepassait les limites de ses compétences, Simard y alla d'une charge à fond de train contre les « nationalismes religieux qui [avaient] été avertis à maintes reprises de ne pas engager les forces vives de l'Église dans les luttes de langue ou de race $^{47} »$. Si le catholique avait le droit de combattre l'État dans la mesure où une injustice avait été commise, il lui était

versité d'Ottawa [dorénavant RUO], 1931, p. 5.

45. Georges Simard, «L'enseignement français au Canada », RUO, 1932, p. 223.

46. Georges Simard, «La race et la langue françaises dans l'Église du Canada», RUO, 1933, p. 131-154. Le père Simard mobilisa fréquemment la théologie augustinienne - en particulier La Cité de Dieu - pendant les années 1930 pour analyser diverses questions politiques canadiennes et pour appeler à un rapprochement entre franco-catholiques et irlando-catholiques. Voir, par exemple, « Saint Augustin, apôtre de la paix : relations de l'Église et de l'État au Canada » dans Études canadiennes. Éducation, politique, choses d'Église, Ottawa, Éditions de l'Université d'Ottawa, 1938, p. 191-218.

47. Georges Simard, «La race et la langue françaises dans l'Église du Canada », RUO, 1933, p. 136. 
interdit, en revanche, de le faire en tant que fidèle, tant et aussi longtemps que la Cité terrestre, encore une fois, ne se mêlait pas des affaires de la Cité céleste, et qu'elle agissait à l'intérieur de la sphère temporelle qui était la sienne ${ }^{48}$. Ce raisonnement n'était pas sans rappeler celui qu'avait adopté le pape dans ses encycliques sur la crise scolaire franco-ontarienne (1916 et 1918) - documents auxquels se référa d'ailleurs le père Simard -, à savoir que le problème du Règlement 17 était un problème strictement politique, qu'il ne s'agissait aucunement d'un enjeu religieux. Cette thèse avait été soutenue, rappelons-le, à l'encontre de celle des nationalistes canadiens-français, qui croyaient la question nationale intrinsèquement liée à la question religieuse, tout en lui étant clairement subordonnée. Le père Simard renvoya aussi à La Primauté du spirituel du philosophe néothomiste et personnaliste Jacques Maritain, qui avait déjà pris ses distances par rapport à l'absolutisation du politique et à l'instrumentalisation du catholicisme qui caractérisaient les thèses maurrassiennes - thèses justement condamnées par le Saint-Siège, souligna notre oblat - et qui soutenait à présent que l'Église devait se tenir loin de la joute politique, qu'il lui fallait récuser toute « passion brûlante pour un parti - qu'il [fût] démocratique, nationaliste ou raciste ${ }^{49} »$, qu'il lui appartenait plutôt, autrement dit, de veiller aux affaires de la Cité céleste. « L'Église n'a pas reçu mission de sauver les races, les peuples et les langues ${ }^{50} »$, renchérit le père Simard à l'encontre, vraisemblablement, de ses anciens compagnons du mouvement nationaliste. La thèse de la langue, «gardienne » de la foi étaitelle toujours recevable? Il était permis d'en douter, le « dualisme foncier ${ }^{51} \gg$ de l'Église canadienne imposant plutôt le respect dû à ses deux composantes ethnolinguistiques, canadienne-française et irlandaise. Surtout, l'œuvre missionnaire de la diaspora irlandaise dans le monde anglo-protestant lui paraissait impossible à nier, à

48. Ibid., 1933, p. 139.

49. Jacques Maritain, cité dans ibid., p. 139.

50. Ibid., p. 137.

51. Ibid., p. 137-138. 
telle enseigne que, pour le bien de la foi, il était nécessaire de lui reconnaître la place qui lui revenait de droit, malgré la supériorité numérique dont jouissaient les Canadiens français au sein de l'Église canadienne :

Au pays où la population à convertir est surtout anglaise, l'apôtre anglo-saxon ou écossais serait l'idéal. Et vraisemblablement un Newman ${ }^{52}$ canadien orienterait l'âme canadienneanglaise vers les pâturages de l'Église.

À défaut de ce missionnaire, plutôt rare, le celte conviendrait. Qui ne sait que la race irlandaise, martyre dans sa foi depuis quatre siècles, a reçu de Dieu en récompense de sa fidélité l'étrange, l'ironique, la glorieuse mission d'annoncer à ses persécuteurs les vérités de notre sainte religion! Les 26 millions des fils de l'Irlande répandus en Angleterre, en Australie, en Nouvelle-Zélande, dans l'Afrique-Sud, au Canada et aux États-Unis témoignent de cette vocation méconnue par tous les historiens. " Peut-être bien que, pour demeurer fidèles à nos propres principes, faudrait-il admettre qu'un apôtre de même langue devait être placé auprès de la race maîtresse afin de lui rappeler les vérités surnaturelles nécessaires, tenter de la convertir et, en cas d'échec, ménager à la Providence l'argument de justification dont elle aura besoin au jour des rétributions finales ${ }^{53}$. »

Ce raisonnement n'était pas sans rappeler celui de l'archevêque de Westminster, $\mathrm{M}^{\mathrm{gr}}$ Francis Bourne, qui avait soutenu, près de vingtcinq ans plus tôt, en 1910, lors du grand Congrès eucharistique de Montréal, que l'avenir de la foi en Amérique était anglais, et que pour assurer sa propre croissance, l'Église canadienne se devait de le reconnaître sans tarder... L'intervention de Bourne avait déplu souverainement à Henri Bourassa qui, dans un discours qui avait achevé de faire de lui le héros des nationalistes canadiens-français, lui avait offert une riposte en règle faisant valoir le droit d'aînesse des franco-catholiques en Amérique. À l'inverse, Bourne avait été

52. John Henry Newman (1801-1890), cardinal et théologien britannique.

53. Georges Simard, «La race et la langue françaises dans l'Église du Canada », $R U O, 1933$, p. 146-147. Notons que la citation qui figure à la fin de cet extrait est du père Simard lui-même, qui renvoie à un discours prononcé en 1931 et reproduit dans Le Droit, le 22 juin 1931. 
chaudement applaudi par le clergé irlando-catholique de l'Ontario, dont $\mathrm{M}^{\text {gr }}$ Fallon, qui y avait puisé d'importantes munitions dans son combat contre les écoles bilingues de la province, lequel contribuerait au déclenchement de la crise du Règlement 17 deux ans plus tard. Bien entendu, Simard ne cherchait d'aucune manière à justifier le Règlement 17, même s'il soutenait, encore flanqué de Maritain, que l'acceptation d'un préjudice actuel était parfois la condition d'un bien futur, raisonnement qui, s'il l'avait appliqué directement à la résistance franco-ontarienne, l'aurait vraisemblablement discréditée ${ }^{54}$. En revanche, comment ne pas constater la volonté qu'il affichait maintenant de favoriser la réconciliation entre Canadiens français et irlando-catholiques qui, d'adversaires qu'ils avaient été, à ses yeux, quelque vingt ans plus tôt, s'étaient transformés en alliés voués, les uns comme les autres, à la propagation de la foi au pays ? En prêchant le rapprochement entre les deux factions linguistiques qui menaçaient l'unité de l'Église canadienne, Simard se trouvait aussi à repousser, encore une fois, la doctrine du « nationalisme intégral ».

Les prémisses théologiques de sa nouvelle posture intellectuelle le conduisirent à intervenir à plusieurs reprises dans le débat sur l'avenir politique et constitutionnel du Canada français, débat dont l'intensité augmenta, pendant les années 1930, avec l'apparition, en particulier au sein de la jeunesse, de groupes et de publications revendiquant ouvertement la formation d'un « État français » indépendant ${ }^{55}$. Les « séparatistes », estimait Simard, faisaient fausse route en prétendant pouvoir fonder un État indépendant exclusivement sur la « nationalité » canadiennefrançaise, car les « peuples » n'étaient réductibles ni à la « nationalité » ou à la « race », ni à la langue, et encore moins à la religion. Plutôt, les « peuples » étaient l'expression politique d'un « vouloir-vivre collectif», lequel rendait possible, voire désirable, philosophiquement, la réalisation du projet national canadien :

54. Ibid., 1933, p. 150.

55. Yvan Lamonde, La Modernité au Québec. La crise de l'homme et de l'esprit, 1929-1939, Montréal, Fides, 2011, 336 p. 
En cultivant un vouloir-vivre collectif canadien, en devenant un peuple uni, nous fortifierons notre État. [...] Deux races, mieux que cela, deux nationalités, l'une française et l'autre anglaise, s'unissant, sans se confondre, pour former un peuple, voilà le Canada dans son armature fondamentale.

Ce qui montre assez que pour nous, il ne saurait être question de choisir entre Canadiens, d'une part, et Canadiens français ou Canadiens anglais, d'autre part. Canadien est notre nom de peuple ; canadien[-] français ou canadien[-]anglais notre nom de nationalité ; français ou anglais notre nom de race ${ }^{56}$.

Ces réflexions, relevons-le, évoquent certains aspects de la pensée d'Henri Bourassa, que les positions romaines sur la question du nationalisme, pendant l'entre-deux-guerres, avaient aussi contribué à faire évoluer... À l'approche du Deuxième Congrès de la langue française de Québec, en 1937, alors que la controverse entourant le « séparatisme » canadien-français faisait couler plus d'encre que jamais dans les milieux intellectuels du Canada français, le père Simard mobilisa à nouveau son théologien fétiche pour mettre les nationalistes au pas et se porter à la défense du régime fédéral canadien. La théorie du « vouloir-vivre collectif», il la fit remonter directement, cette fois, à l'auteur de La Cité de Dieu, qui faisait reposer « la cause formelle des États » sur « [1]'union, dans l'amour raisonné, des biens capables d'assurer la félicité commune » :

La géographie, l'histoire, la langue, la religion, la nationalité ne sont donc pas de soi aptes à constituer automatiquement les sociétés politiques. Il y faut l'amour commun, le choix libre, l'acceptation volontaire, le vouloir-vivre collectif. Où ce « formel » manque, il ne saurait y avoir de véritable État. Où il est, l'État peut exister, quelle que soit la combinaison des premiers biens, qui ne sont après tout que la matière dont se nourrissent les humains.

En somme, il est clair que saint Augustin constitue les États avec des éléments tous objectivement bons, des éléments légitimement désirables par des volontés droites et par un amour

56. Georges Simard, «La race et la langue françaises dans l'Église du Canada », RUO, 1933, p. 142-143. 
honnête. Rien dans ces buts, ontologiques ou psychologiques, qui fasse suite aux passions, contrairement à ce qui arrive d'ordinaire dans l'édification des empires, ces échafaudages arbitraires et gigantesques ${ }^{57}$.

Cet extrait permet de constater que, dans la théologie et la philosophie politique du père Simard, le fondement de toute société était d'abord et avant tout matériel, et non culturel ou « racial », contrairement à ce qu'auraient prôné les « séparatistes », fallaitil conclure, car elle devait permettre à ses membres de pourvoir sans entraves à leurs besoins, tout en reposant, encore une fois, sur la «volonté » partagée de cultiver le bien commun par la solidarité et l'entraide. Le devoir de s'organiser en société ou en État était donc un devoir naturel, poursuivit Simard, sollicitant cette fois Aristote. Ces réflexions l'autorisèrent aussi à conspuer " l'édification des grands empires », nécessairement hégémoniques et spoliateurs, et fondés sur la domination que seule la force permettait au vainqueur d'exercer sur le vaincu. Simard fouilla encore dans la théologie de l'évêque d'Hippone pour y exhumer sa « théorie des États moyens », dont le Canada lui semblait fournir un fort bel exemple. « [F]ruits naturels des légitimes aspirations des hommes », les « États moyens » s'opposaient «à la conception d'un monde où de vastes empires, effets fréquents de la cupidité, de l'ambition, de l'amour du commandement ou de la gloire, impos[ai]ent leur domination, moins pour servir que pour se servir ${ }^{58} \gg$. Se rangeant derrière la figure tutélaire du juriste français Louis Le Fur, Simard réitéra sa définition de la notion de « peuple », dont l'acception contemporaine désignait non pas une « communauté d'origine », mais plutôt une « même organisation politique », ou un «État», tout simplement ${ }^{59}$. Encore une fois, le Canada, «État moyen » par excellence, lui paraissait constituer sans ambiguïté un authentique « peuple » : ni limité à

57. Georges Simard, " Principes et faits en histoire. État idéal et État canadien », RUO, 1937, p. 266-267.

58. Ibid., p. 267.

59. Ibid., p. 270. 
l'exclusivité raciale de quelque groupe que ce fût, ni fondé sur la loi du plus fort ou sur les velléités de domination d'un groupe aux dépens de l'autre, le régime canadien permettait, pour peu qu'on le voulût, à ses composantes « raciales », « ethniques » ou «nationales »- termes interchangeables, dans son discours - de coexister et de se porter mutuellement secours, soudées d'abord par la « justice légale », puis par la « justice distributive » : «Tel est donc notre État : un édifice politique, créé, sans doute, par l'Angleterre, à notre demande instante, mais un édifice reposant sur la loi naturelle et sur la loi éternelle, édifice stable de par ces lois divines et contre lequel les consciences ne sauraient inconsidérément s'insurger ${ }^{60}$. $\gg$ Au final, tout ce que contenait la définition augustinienne de l'État moyen, État « idéal », « se retrouv[ait] [aussi] dans l'organisation de notre État canadien ${ }^{61} »$. Avec une bénédiction provenant de si haut, qui aurait pu s'en prendre à l'intégrité du régime constitutionnel canadien?

Pourtant, un « malaise » troublait bel et bien le pays, en raison de ce que la « justice distributive » n'était pas toujours « respectée » « dans le partage des honneurs, des dignités et des biens communs [parmi les] majorités fédérales $\rangle^{62}$. Mais la solution à ce malaise n'était pas pour autant la création d'un « État français » indépendant, s'empressa d'ajouter Simard, qui redoubla d'ardeur pour démolir la thèse séparatiste. Rejetant d'emblée le principe des nationalités (qu'il attribua confusément à Rousseau), soit l'idée que " chaque nation a[vait] le droit de se former en État distinct », Simard revint à Le Fur, ainsi qu'au théologien dominicain Joseph Thomas Delos et à son confrère jésuite Yves de la Brière, pour soutenir que la «mission culturelle » des minorités nationales pouvait très bien s'accomplir en marge de l'indépendance politique, et que remettre en cause l'ordre social en le confiant à « un principe [aussi] mouvant, orageux [et] difficilement praticable » que le principe des nationalités condamnerait à

60. Ibid., p. 271.

61. Ibid., p. 272.

62. Ibid., p. 272. 
l'anarchie ${ }^{63}$. D'ailleurs, la « violence », conséquence inévitable du séparatisme, constituerait toujours une manière illégitime de résoudre les querelles à caractère culturel qui pouvaient sévir à l'intérieur d'un même État. Citant encore Maritain, Simard exposa les limites, telles qu'il les percevait, des « revendications d'autonomie nationale », qui n'avaient de légitimité que dans la mesure où elles se subordonneraient aux « idées et [aux] biens supérieurs $»^{64}$ : «Plus encore que les personnes, les peuples doivent se soumettre à l'ordre inexorable de la morale et du pratico-pratique. La nationalité canadienne-française autant que les autres ${ }^{65}$. » Dans sa volonté de conspuer tous les arguments qui pouvaient servir d'appui au séparatisme, le père Simard poussa l'audace jusqu'à s'en prendre à l'une des vaches les plus sacrées des milieux intellectuels et politiques du Canada français depuis la fin $\mathrm{du} \mathrm{XIX}^{\mathrm{e}}$ siècle, soit la thèse des deux peuples fondateurs du pays ${ }^{66}$. Au contraire, fit-il valoir, l'idée faisant de l'Acte de l'Amérique du Nord britannique (AANB) de 1867 un «pacte » dont le Québec aurait été l'une des parties contractantes était une fausseté que l'on pouvait prouver sans grande difficulté, à son avis. Seuls les États souverains étaient habilités à établir des relations réciproques - et d'y mettre fin - par l'entremise de cet outil juridique qu'était le pacte. Les colonies britanniques qui s'étaient réunies à Charlottetown et à Québec en 1864 avaient donc été « impuissantes à conclure entre elles un contrat, un traité, un pacte créant un nouvel ordre politique ${ }^{67} \gg$. Seule la GrandeBretagne possédait cette prérogative, de sorte que l'AANB n'était pas un pacte, mais une simple loi adoptée par le Parlement de Westminster, bien qu'il le fît, s'empressa-t-il d'ajouter, à la demande de ses colonies nord-américaines. Autrement dit, le seul

63. Ibid., p. 274.

64. Ibid., p. 275.

65. Ibid., p. 277.

66. Voir, là-dessus, Arthur Silver, The French Canadian Idea of Confederation, 1864-1900, Toronto, University of Toronto Press, 1982, 257 p.

67. Georges Simard, « Le Canada d'aujourd'hui et de demain », RUO, 1938, p. 147. 
État qui existât au Canada était l'État... canadien. Se rangeant de nouveau derrière Le Fur, Simard enfonça le clou en affirmant que le droit de sécession n'appartenait pas aux « collectivités fédéralisées »- mais à qui pouvait-il donc appartenir, dans ce cas ?-, lesquelles n'étaient pas autorisées à l'invoquer, pas plus que le principe des nationalités, pour obtenir la reconfiguration de l'ordre politique existant.

Le légalisme du père Simard en cette matière ferait l'objet d'une critique sévère, quelques années plus tard, par l'économiste et père jésuite Richard Arès, l'un des principaux penseurs, avec Esdras Minville et François-Albert Angers, du corporatisme social au Canada français et l'un des maîtres à penser de l'école groulxiste pendant et après la guerre : « les arguments juridiques que l'on oppose [à la thèse du pacte] », écrirait-il, «peuvent facilement se rétorquer par des arguments aussi forts et aussi probants ; quant aux arguments philosophiques ou théologiques, ils sont, semble-t-il, ou de fausse portée ou sujets à d'interminables discus$\operatorname{sions}^{68}{ }^{6}$. Des considérations supplémentaires empêchaient toutefois Simard de voir dans le « séparatisme » une solution légitime aux problèmes politiques et nationaux du Canada : l'inévitable opposition de la majorité, la faible viabilité d'un éventuel Québec indépendant, le sort qui serait fait aux « groupes [de langue française] disséminés sur le territoire canadien », argument qu'il développa à maintes reprises au cours de ces années : «Pourquoi l'opposition des Franco-Canadiens dispersés pèserait-elle moins dans les plateaux de l'équité que le sentiment d'une poignée de Franco-Québécois ? Pour les "évincés", il y a là une question de vie ou de mort ${ }^{69} »$. Et Simard de boucler la boucle, car le dernier argument qu'il mobilisa pour contrer la thèse séparatiste était la menace que la rupture du régime confédéral lui paraissait contenir

68. Richard Arès, Dossier sur le pacte confédératif [1941], cité dans Pierre Trépanier, "Richard Arès », L'Action nationale, février 1992, p. 179. Voir aussi Richard Arès, « La Confédération : pacte ou loi? », L'Action nationale, décembre 1949, p. 250.

69. Georges Simard, « Principes et faits en histoire. État idéal et État canadien », RUO, 1937, p. 278. 
pour l'avenir et la puissance de l'Église au pays. Le catholicisme, par définition universel, devait ainsi transcender la question nationale, c'est-à-dire la sphère temporelle :

Le simple bon sens croit comprendre que l'Église canadienne, dans son ensemble, s'amoindrirait grandement du fait de la scission prônée. C'est son unité et son importance numérique globale qui lui attirent le respect dans le Dominion et dans les provinces où les fidèles, nécessairement disséminés, ont à se défendre contre l'irréligion, le fanatisme, voire des lois outrageantes et persécutrices. Or, quand « les bases de la foi et de la civilisation chrétiennes sont menacées », est-ce le temps de « fractionner les forces catholiques » [Pie XI] ? Que l'on considère les équipées sanglantes du nationalisme contemporain, l'alliance rouge des malheureux Basques; que l'on pense aux avertissements si graves du pape et des évêques touchant les dangers du communisme. Peut-être s'apercevra-t-on que le plus impérieux de nos devoirs n'est pas précisément une division de notre nationalité. Vraiment, nos origines mystiques, notre mission religieuse en Amérique ne mériteraient-elles rien de mieux que de finir dans un reploiement douloureux après un envol si grandiose ? Prenons garde qu'ici le « national » croise le « catholique $»^{70}$.

Non, le séparatisme était à proscrire, réitéra Simard : là-dessus, le droit naturel, la morale et les intérêts supérieurs de l'Église et du catholicisme ne permettaient aucune méprise. En outre, « les droits de civilisation de l'État canadien l'emport[ai]ent de beaucoup sur nos droits culturels qui, en tant que tels, n'exige[ai]ent pas nécessairement l'indépendance politique et [pouvaient] être pratiqués convenablement, même avec un compagnonnage racial ou national différent ${ }^{71} »$. En revanche, pour résoudre les problèmes de la vie politique du pays, il était impératif qu'une élite émanant des deux grandes nationalités qui constituaient le peuple canadien et « instruite dans les sciences philosophiques, théologiques, juridiques et historiques s'emplo[yât] à [les] élu-

70. Ibid., p. 280.

71. Georges Simard, "Le Canada d'aujourd'hui et de demain », RUO, 1938, p. 158. 
$\operatorname{cider}^{72} »$. Or cette élite n'émergerait pas spontanément de la société canadienne sans que le terrain fût préparé par la mise sur pied d'un système d'instruction voué à la réalisation d'une « œuvre de haute compréhension, propre aux deux races mères de la patrie » : « J'affirme bonnement ceci : quand un idéal commun doit informer et associer par le haut deux races distinctes, il est nécessaire que cet idéal soit enseigné à tous, soit connu et aimé de tous, soit respecté et vénéré par tous. Dans n'importe quel système de gouvernement, fût-ce la confédération, l'unité du pays et du peuple canadien est attachée à ce prix ${ }^{73}$. » Et au chapitre de la « haute compréhension », l'Université d'Ottawa avait un rôle crucial à jouer, un rôle qui engageait l'avenir même du pays, car, en son sein, la coexistence, qui reposait sur l'unité que commandait l'Église aux fidèles, avait été élevée au rang des principes fondateurs et indiscutables :

Les Canadiens outaouais, qu'ils soient de l'une ou de l'autre langue, se rendent-ils bien compte que c'est à eux que reviennent, spécialement, l'étude et l'approfondissement des problèmes dont la solution maintiendrait meilleures la cohésion et la consistance de l'État et de la patrie ? [...] [Q]ui que nous soyons, nous devons admettre que, seule, l'union dans la justice et dans la charité des groupes canadiens pour lesquels l'Université d'Ottawa a été créée et subsiste permettra aux maîtres qui en ont la charge de conduire à bon terme leurs espoirs, leurs labeurs, leur incontestable bonne volonté ${ }^{74}$ ?

Si le père Simard vouait un véritable culte à saint Augustin, il s'inspirait aussi de saint Thomas, quoique dans une moindre mesure, pour encadrer, philosophiquement et théologiquement, ses méditations politiques. Le contraire eût été étonnant, étant donné la place qu'occupait le thomisme dans le contexte religieux de la première moitié du $\mathrm{Xx}^{\mathrm{e}}$ siècle au Canada français ${ }^{75}$. Un article

72. Georges Simard, « Principes et faits en histoire. État idéal et État canadien », RUO, 1937, p. 284.

73. Georges Simard, « Propos d'éducation nationale», RUO, 1935, p. 30.

74. Georges Simard, « La doctrine catholique et les universités. L'Université d'Ottawa, 1889-1939», RUO, 1939, p. 173, 174.

75. Le théologien Simard s'affairait aussi, à ses heures, à dévoiler les conver- 
publié en 1938 dans la Revue de l'Université d'Ottawa intitulé simplement «Le Canada d'aujourd'hui et de demain » en fournit un bon exemple. En rappelant que le docteur angélique avait bien saisi que l'homme était « constitué débiteur » envers Dieu, qui était « le premier principe d'être et de gouvernement», mais aussi envers d'autres «personnes » « selon les différents degrés de perfection qu'elles poss[édaie]nt et les bienfaits différents » qu'il avait reçus d'elles, Simard conclut à la nécessité certaine du patriotisme, qu'il rattacha « à cette vertu de justice que la théologie dénomme piété » :

[A]près Dieu, l'homme est surtout redevable à ses parents et à sa patrie. En conséquence, de même qu'il appartient à la religion de rendre un culte à Dieu, de même, à un degré inférieur, il appartient à la piété de rendre un culte aux parents et à la patrie. D'ailleurs, le culte des parents s'étend à tous ceux du même sang, c'est-à-dire qui ont les mêmes parents ; le culte de la patrie s'entend des compatriotes et des alliés [sic]. C'est donc à ceux-là que s'adresse principalement la piété ${ }^{76}$.

La patrie, selon ce que Simard retenait du thomisme, n'était rien d'autre que le prolongement de la famille qui exerçait à une plus vaste échelle le rôle qui incombait naturellement aux parents : donner la vie et veiller au bien-être et au développement de la personne ${ }^{77}$. En contrepartie, le thomisme exigeait que l'on rendît à la patrie, comme aux parents, "le culte et le service». Or l'intensité de ce culte pouvait varier, encore une fois, « selon les différents degrés de perfection [de son destinataire] et les bienfaits différents » que la personne avait reçus de lui, de sorte qu'il était normal qu'elle variât aussi selon les différentes appartenances

gences entre les doctrines augustinienne et thomiste. Voir Georges Simard, « Les thomistes et saint Augustin », RUO, 1936, p. 5-21. Sur le thomisme, voir, notamment, E.-Martin Meunier, Le Pari personnaliste. Modernité et catholicisme au XX' siècle, Montréal, Fides, 2007, 369 p. ; Florian Michel, La Pensée catholique en Amérique $d u$ Nord. Réseaux intellectuels et échanges culturels entre l'Europe, le Canada et les États-Unis (années 1920-1960), Paris, Desclée De Brouwer, 2010, 629 p. p. 151.

76. Georges Simard, « Le Canada d'aujourd'hui et de demain », RUO, 1938,

77. Ibid., p. 152-153. 
qui se manifestaient invariablement au sein d'un État fédéral et binational comme le Canada. Ainsi, « provincialisme » et « nationalisme », pour légitimes qu'ils fussent, devaient clairement se subordonner au " véritable patriotisme », qui les englobait et les transcendait à la fois :

La piété patriotique embrassera donc dans sa justice affectueuse ou dans ses justes affections la patrie tout entière. Mais elle saura distinguer spécialement la province et la nationalité, donnant au provincialisme et au nationalisme leur légitimité et leur rang dans l'échelle des valeurs sociales. Et dès là [sic] que provincialisme et nationalisme ne sont que des modalités essentiellement inhérentes à la substance du véritable patriotisme, il s'ensuit qu'ils ne peuvent prendre le pas dans le culte et le service de la patrie commune. S'il arrivait jamais que les parties dussent l'emporter sur l'intégrité de l'ensemble dont elles dépendent, c'est que, ce jour-là, une nouvelle patrie se formerait des lambeaux d'une patrie déchue. À nous d'y penser si nous ne voulons que le Canada cesse d'être notre Canada ${ }^{78}$.

\section{III - Le passage aU loyalisme et le débat Simard-LaURendeau}

Nous avons vu, jusqu'ici, que le père Simard tâchait de fonder sa philosophie politique sur des assises théologiques, surtout augustiniennes, mais aussi thomistes, lesquelles se voulaient conformes aux prises de position qu'avait multipliées Rome sur la question du nationalisme depuis les années 1910. À ces arguments s'en ajoutèrent d'autres, plus « classiques », pour ainsi dire, et propres au champ intellectuel du Canada français, qui lui permirent de redoubler d'ardeur dans son combat contre ce qu'il considérait comme la menace du séparatisme. Toujours dans ce même article de 1938, Simard étala devant ses lecteurs un loyalisme sans complexe en exhumant, étonnamment, la vieille thèse de la Conquête providentielle de la Nouvelle-France. Depuis l'essor qu'avait connu le groulxisme dans l'arène intellectuelle du Canada français, peu d'intellectuels et de polémistes, hormis le sénateur et historien vieillissant Thomas Chapais, osaient encore

78. Ibid., p. 154. 
soutenir cette interprétation de la chute du Régime français, une interprétation fort ancienne selon laquelle la Conquête britannique avait mis la colonie à l'abri des horreurs de $1789^{79}$. Simard, qui ne reculait devant aucun anachronisme, n'en avait cure :

Nous sommes attelés ensemble au timon d'un même État fédéral pour le développement de nos nationalités respectives et de notre unique patrie. À nous de reconnaître dans la trame de notre histoire le maître « qui tient dans sa main tous les États de la terre» [saint Augustin]. «Est-il croyable que Dieu, qui ne laisse rien, pas même la structure du plus vil insecte, la plume de l'oiseau, la moindre fleur des champs, la feuille de l'arbre, sans la convenance et l'étroite union de ses parties, ait voulu abandonner les royaumes des hommes, leurs dominations et leur servitudes en dehors des lois de sa providence ? » [saint Augustin]. C'est notre sort de vivre à côté d'un peuple différent du nôtre de tant de manières. Mais c'est un sort dans lequel le Seigneur des nations a caché bien des faveurs. N'est-ce pas lui qui nous a épargné les infidélités et les révolutions de la France depuis 1789 ? N'est-ce pas lui qui nous protège contre un envahisseur autrement subtil et vorace et dangereux ? Certes, nous sommes à une école où l'art du gouvernement nous est enseigné rudement, où notre adolescence se mûrit avec peine et avec gêne. Traités un peu à la manière des Juifs de la cour des Pharaons, peut-être comme eux nous préparons-nous un avenir que nous n'entrevoyons pas bien et qui pourrait être infiniment plus beau qu'une Laurentie resserrée et étroite. Personne ne sait ce que la géologie, aux lois mystérieuses, réserve à l'Ouest canadien. Un Canada plus replié sur lui-même aura infiniment de chances de grandir dans le sens de notre foi, de notre langue et de nos institutions. Si c'était cela que Dieu - « qui établit les royaumes » [saint Augustin] - réservait aux rejetons de la

79. Michel Bock, "Overcoming a National "Catastrophe": The British Conquest in the Historical and Polemical Thought of Abbé Lionel Groulx », dans Philip Buckner et John Reid (dir.), Remembering 1759: The Conquest of Canada in Historical Memory, Toronto, University of Toronto Press, 2012, p. 161-185 ; Michel Ducharme, «Interpreting the past, Shaping the Present, and Envisioning the Future : Remembering the Conquest in Nineteenth-Century Québec », dans Philip Buckner et John Reid (dir.), op. cit., p. 136-160 ; Damien-Claude Bélanger, « Thomas Chapais, loyaliste ", Revue d'histoire de l'Amérique française, vol. 65, nº 4 (printemps 2012), p. $439-472$. 
veille France, nos séparatistes - car il s'en trouve - seraient bien attrapés d'avoir rêvé si petit et si mesquin ${ }^{80}$.

Le raisonnement du père Simard semblait se faire de plus en plus sinueux, pour ne pas dire spécieux. D'une part, saint Augustin nous avait appris que les empires étaient un mal, car fondés sur la domination qu'exerçaient les États les plus puissants sur les plus faibles, et qu'il fallait ainsi leur préférer les « États moyens ». D'autre part, la Providence avait permis et voulu que la NouvelleFrance passât aux mains de l'Empire britannique - lequel avait pourtant tourné le dos à l'Église - afin qu'elle fût préservée des affres de 1789. Quelques mois après le déclenchement de la Deuxième Guerre mondiale, les adversaires intellectuels du père Simard ne manqueraient pas de relever les apories qu'ils croyaient déceler dans sa pensée. Le prétexte de cette dénonciation leur viendrait sous la forme d'un article intitulé « Le mal et les Empires » qu'avait publié le théologien de l'Université d'Ottawa au début de 1940 et dont l'objectif avait été de montrer que le conflit naissant avait " acculé » le monde " à la nécessité d'une nouvelle croisade ${ }^{81} \gg$. Simard avait-il lancé un plaidoyer en faveur de la guerre, s'était-il même rangé dans le camp des impérialistes britanniques au moment où les milieux nationalistes du Canada français, qui souhaitaient éviter avant toutes choses une réédition de la crise de la conscription de 1917, restaient sur leurs gardes et jaugeaient la situation canadienne et mondiale avec autant de modération que de circonspection ? Le principal intéressé s'en défendit en affirmant qu'il avait voulu produire « un essai purement théologique » dont il ne fallait tirer aucune « conclusion politique », bien qu'il eût convenu qu' « entre les fins religieuses et profanes de l'histoire, il ne saurait y avoir de cloison étanche $»^{82}$. Pourtant, à la lecture du texte, il était difficile ne de pas y voir un appui à la guerre, à la Grande-Bretagne et à l'Empire britan-

80. Georges Simard, «Le Canada d'aujourd'hui et de demain », RUO, 1938, p. $162-163$.

81. Georges Simard, « Le mal et les Empires », RUO, 1940, p. 135-136.

82. Ibid., p. 138. 
nique dans son ensemble. Certes, sur la question des empires, la position de l'évêque d'Hippone, son éternel compagnon de route, était claire : « [E]n soi, les Empires sont un mal », répéta-t-il, « quelquefois un grand mal, qui asservit l'homme à l'homme, les peuples aux peuples, au prix de leur dignité, de leur liberté et, souvent, de la justice et de la paix ${ }^{83}$. » Or il n'en demeurait pas moins que c'était Dieu lui-même qui avait « voulu et fait les Empires $^{84} »:$ : Plus précisément encore : c'est la Providence qui a donné à l'Angleterre l'Empire et au Canada - jusqu'au Statut de Westminster (?) - l'assujétissement [sic] d'une colonie ${ }^{85}$. " En vertu du " principe de causalité », toutes les " créatures » s'enchaînaient, les « moins parfaites » s'ordonnant aux «plus parfaites » : « le minéral à la plante, la plante à l'animal, l'animal à l'homme, l'homme à la société politique, la société politique à l'Église et celle-ci à Dieu dont elle a reçu pour mission de procurer la gloire en façonnant des élus. Si bien que tout ici-bas gravite vers l'Église et, par elle, vers Dieu ${ }^{86} »$. Les desseins surnaturels de la Providence étaient insondables, cela allait de soi, mais cela n'excluait pas que les hommes en fussent des acteurs de premier plan, des « collaborateurs ». Même les empires, pourtant un « mal » en soi, agissaient dans le sens de leur réalisation, car eux aussi devaient se plier au principe de causalité :

Tantôt Dieu agit au fond des cœurs, dans l'intimité de la vie de chacun, tantôt il mène les hommes sur le plan de la vie publique, prêtant à leurs qualités ou à leurs passions le concours de son action, soit qu'il veuille ériger des nations de grandeur moyenne, soit qu'il ait en vue l'élévation de quelques puissances formidables pour assurer l'évolution ou la sécurité du monde lui-même. Car, et il faut bien retenir cette proposition, formulée par saint Augustin, mais pleine de toute la vérité de la philosophie, de la théologie et de la foi catholiques : «Dieu dispense la grandeur des Empires au besoin des temps que sa

83. Ibid., p. 132.

84. Ibid., p. 132.

85. Ibid., p. 133.

86. Ibid., p. 133. 
providence gouverne. » En d'autres termes, Dieu taille, bâtit les Empires, ou plus vastes ou moins vastes, selon les desseins qu'il a décidé d'accomplir. D'où il suit qu'à mesurer la grandeur visible des Empires, l'on découvre la grandeur invisible de la politique divine ${ }^{87}$.

«Dieu dispense la grandeur des Empires au besoin des temps que sa providence gouverne. » Babylone, Rome, le Saint-Empire romain, l'Empire napoléonien, même l'Empire allemand de 1870, tous avaient été érigés pour accomplir une partie du plan que la Providence, qui s'incarnait dans l'Histoire, avait échafaudé pour l'humanité. En 1940, le « besoin des temps » avait rarement été aussi urgent. «Nazisme et communisme, c'est-à-dire idolâtrie de la race et de la classe, culte du sang et du prolétariat, voilà où le monde chrétien en est réduit. [C]'est le sort de Dieu, de l'Évangile et de la véritable civilisation qui est en cause ! Serions-nous donc acculés à la nécessité d'une nouvelle croisade ${ }^{88}$ ? $\gg$ La guerre de 1939, celle qu'il fallait faire au nazisme et au communisme, était donc, à ses yeux, une « croisade », c'est-à-dire une guerre sainte. Mais « [q]ui donc [allait] jouer le rôle de croisés ?», s’inquiéta-t-il avant de rassurer son lecteur : «Aux grands maux [la Providence] applique les grands remèdes. [P] our les causes majeures, elle prépare des agents irrésistibles. " Et le père Simard de nommer expressément les empires britannique et français, dont la « si haute puissance » ne devait pas être vaine et que Dieu avait « accordé[s] à notre siècle pour les besoins de son gouvernement $\|^{89}$. « Absolument parlant », les empires étaient un « mal », répéta-t-il, et découlaient de la « faute originelle ». Or, « dans l'ordre de la chute et de la réparation », ils étaient un « bien, un bien relatif dont Dieu se ser[vai]t, soit pour punir ou récompenser les nations et les conquérants, soit pour dresser ou stimuler les races et les chefs qu'il destin[ait] aux premiers rôles de l'histoire ${ }^{90} »$. À la fois « policiers et justiciers de Dieu », les empires «mett[aie]nt

87. Ibid., p. 133-134. Les italiques sont de Simard.

88. Ibid., p. 133-136.

89. Ibid., p. 136.

90. Ibid., p. 137. 
de l'ordre entre les petits États trop brouillons, et assur[aie]nt l'évolution de l'humanité » vers l'accomplissement de ses grands desseins ${ }^{91}$. La cause de la guerre était donc bel et bien " sacrée », le « petit peuple» canadien ne devait pas s'y laisser méprendre :

Jamais Dieu, à ma connaissance, n'a eu en main pour une cause noble et sacrée des instruments de cette force, de cette compétence et de cette détermination.

Aussi est-il à souhaiter que les deux métropoles auxquelles nous tenons, soit par le sentiment, soit par le loyalisme, et plus encore par l'héritage commun de la même civilisation chrétienne, puissent remplir le rôle auquel les convie la Providence ${ }^{92}$.

Le père Simard conclut son essai en exhortant ses compatriotes à placer leur foi dans la « juste Providence », qui n'oublierait pas de « rétribuer ici-bas, par le succès même matériel, nos vertus et nos mérites d'ordre public ${ }^{93} »$. L'appui à la guerre, le patriotisme canadien et la loyauté envers l'Empire britannique étaient ainsi élevés au rang des devoirs qu'exigeait impérieusement de ses fidèles le Très-Haut... Dans le camp nationaliste, sans surprise, les réactions à cette prise de position de Simard ne se firent pas attendre. La riposte fut publiée le mois suivant dans les pages de la revue montréalaise L'Action nationale, sous la plume trempée au vitriol de son directeur, nul autre qu'André Laurendeau. Ne goûtant pas que l'on pût enrégimenter la Providence dans l'effort de guerre de manière aussi cavalière, voire éhontée, Laurendeau s'appliqua à réduire en cendres la « théologie aventureuse » du père Simard. La guerre contre l'Allemagne nazie était une « croisade » ? « C'est un abus de mots contre lequel un chrétien a le devoir de protester ${ }^{94}$. » Il n'était pas inhabituel, malheureusement, que les politiciens « usurpent ainsi le langage de la théologie » et accoutument le public de leurs «mensonges », mais lorsque c'était un théologien, " et un théologien réputé », ajouta-t-il avec

91. Ibid., p. 137.

92. Ibid., p. 136.

93. Ibid., p. 138.

94. André Laurendeau, "Les jeux d'une théologie aventureuse », L'Action nationale, mai 1940, p. 344. 
une pointe de dérision, qui commettait « la même exagération », c'était « une autre affaire » et il fallait « dresser l'oreille » :

Or voici que le P. Georges Simard [...] soutient des propositions fort aventureuses. L'auteur y accomplit une série de sauts périlleux où en trois bonds, plus ou moins légers, il nous conduit aux apophtegmes suivants : les Empires sont un mal en soic'est Dieu qui veut et fait les Empires - les Empires peuvent être les instruments privilégiés de la Providence divine. Cette acrobatie théologique vous donne le vertige ? N'ayez crainte : on prétend vous conduire en terrain plat, par des sentiers avec lesquels la propagande nous a familiarisés depuis des mois, et ni le style ni la pensée du P. Simard ne sont vertigineux ${ }^{95}$.

Quoi, les empires sont un mal et c'est Dieu lui-même qui les aurait faits et voulus ? Cela semblait une réfutation en règle de la théodicée la plus élémentaire qu'apprenait tout collégien. Et c'est ce même Dieu qui aurait voulu, par ailleurs, que la NouvelleFrance fût intégrée à l'Empire britannique, qui avait tourné le dos à l'Église ? Laurendeau, impitoyable, n'en démordrait pas : le providentialisme de Simard « extravaguait» :

Nous ne sommes pas hérétiques, et nous croyons comme lui, profondément, à l'action providentielle. Mais cette action est mystérieuse ; son cheminement nous paraît souvent obscur ; même après coup, nous ne savons pas toujours lire ce qui était écrit. Bref, nous ne sommes pas dans les secrets de Dieu. Qu'en 1760 , notre passage des mains d'une métropole officiellement catholique en celles d'une métropole officiellement protestante ait accompli les desseins mystérieux de la Providence, je le crois, mais sans être sûr de savoir pourquoi. Que la bolchevisation de la Russie, que l'écrasement de la Pologne et de la Hollande, ou si l'on veut aller encore plus loin, que le martyre des clercs mexicains et espagnols demeurent dans l'axe providentiel, je le crois encore, mais sans comprendre - et surtout sans rendre grâce aux bourreaux. C'est tout le problème du mal moral qui se pose alors, et que je n'aurais pas la témérité de prétendre résoudre... ${ }^{96}$

95. Ibid., p. 345.

96. Ibid., p. 346-347. 
Autrement dit, si la Providence existait, elle avait sûrement mieux à faire que de prendre une part active aux guerres et aux autres mesquineries des hommes... Les arguments qu'opposait Laurendeau à la théologie du père Simard étaient très proches, somme toute, de ceux qu'avait mobilisés son ancien maître, l'abbé Groulx, pour déconstruire, au début du siècle, la thèse de la Conquête providentielle de la Nouvelle-France que défendait son grand rival dans l'arène historiographique, le sénateur Chapais ${ }^{97}$. Surtout, le providentialisme de Simard, à ses yeux, ne pouvait servir à qualifier l'effort de guerre de « croisade » ou de guerre sainte sans franchir les bornes de la décence et de l'humilité les plus élémentaires. La guerre déclenchée en septembre 1939 était une « guerre juste : rien de plus, rien de moins ${ }^{98}$ », affirma le directeur de L'Action nationale, citant à son tour Jacques Maritain, le philosophe de l'heure dans les milieux catholiques. La Providence n'y était donc pour rien, n'en déplût au théologien oblat. Sur ce point, les sommités intellectuelles de l'Église s'accordaient. À preuve, l'avis du chanoine et théologien belge Jacques Leclercq, qui était formel : il fallait « désolidariser la guerre de la religion », la première ayant commencé sans qu'aucune « valeur religieuse » ne fût intervenue ; la « patrie » cherchait naturellement à mobiliser toutes les ressources, y compris « la religion et l'Église », mais les catholiques avaient le devoir de résister à tout effort visant à mettre l'Église « au service des intérêts temporels »; enfin, si tous devaient « servir le Christ », conclut le chanoine Leclercq, « nul n'a[vait] le droit de se servir du Christ; nous devons défendre farouchement l'indépendance de notre vie chrétienne ${ }^{99} »$. La caution philosophique et théologique de Maritain et de Leclercq aurait pu suffire à Laurendeau, mais le directeur de L'Action nationale avait préféré se prévaloir aussi de la « compétence et [de] l'autorité d'un [autre] clerc », qu'il refusa de nommer mais

97. Michel Bock, « Overcoming a National "Catastrophe” », op. cit., p. 161-185.

98. André Laurendeau, "Les jeux d'une théologie aventureuse », L'Action nationale, mai 1940, p. 348.

99. Jacques Leclerc, cité dans André Laurendeau, «Les jeux d'une théologie aventureuse ", L'Action nationale, mai 1940, p. 349. Les italiques sont de l'auteur. 
dont il reproduisit in extenso une lettre pulvérisant l'essai du père Simard. « Cousu d'incohérences et de confusions », « simpliste » et « inexact », l'article de l'oblat comportait un « vice radical » qui « consist[ait] à mettre sur un pied d'égalité le bien et le mal», comme si la Providence avait pu les vouloir « au même degré et de la même manière ${ }^{100} »$. Et le clerc anonyme de porter le coup fatal en piétinant les plates-bandes du père Simard : « Pourtant, un auteur encore considéré comme un guide assez sûr, saint Thomas d'Aquin, pense, avec saint Augustin qu'il cite, que "le mal moral, le mal du péché, ne peut être voulu de Dieu en aucune manière" 101 ". En un coup de plume, la justification augustinienne et thomiste qu'avait fournie le père Simard à l'effort de guerre et à l'existence même de l'Empire britannique, sans parler du providentialisme de la Conquête de 1760, semblait s'effondrer comme un château de cartes. Mais le correspondant de Laurendeau n'avait toujours pas dit son dernier mot :

Je considère ensuite comme un désordre grave et comme une sorte de mépris des puissances de la grâce la tentative de faire dépendre l'œuvre du rachat et du salut de l'action de tel ou tel gouvernement. Le spirituel détient en lui-même, en sa vertu intrinsèque, sa force d'expansion et de conquête : il a ses moyens à lui, qui ne sont ni la guerre ni la boucherie; il a ses ministres et ses apôtres qui ne sont ni Chamberlain ni Churchill. Il faut singulièrement manquer de confiance en la valeur des réalités surnaturelles pour croire leur sort lié à celui d'un pays [la Grande-Bretagne] qui non seulement flirte avec l'hérésie et le communisme, mais les nourrit en son sein ${ }^{102}$.

Armé d'une telle caution, Laurendeau pouvait pourfendre le père Simard sans crainte. Si lui-même souhaitait ardemment la défaite d'Hitler et qu'il appuyait sans ambages la cause des Alliés, il lui paraissait inadmissible, en revanche, que la Providence fût enrégimentée, comme l'envisageait le théologien oblat, à des fins bassement politiques ou militaires : «C'est au Pape de prêcher

100. Clerc anonyme, cité dans ibid., p. 350, 351.

101. Clerc anonyme, cité dans ibid., p. 351.

102. Clerc anonyme, cité dans ibid., p. 352. 
la croisade », conclut-il. « Et laissons aux propagandes d'écrire des sottises ${ }^{103}$. "

Simard et Laurendeau, cela va de soi, ne partageaient pas les mêmes convictions idéologiques et politiques, le second se révélant moins prompt que le premier à subordonner simplement et sans discussion les intérêts du Canada français à ceux du Canada, et encore moins à ceux de l'Empire britannique. Laurendeau, comme chacun le sait, s'apprêtait d'ailleurs à se lancer dans la mêlée politique et le combat anticonscriptionniste en mettant sur pied, avec l'avocat Maxime Raymond, entre autres, la Ligue pour la défense du Canada, puis le Bloc populaire canadien. Toutefois, le fossé qui les séparait était aussi imputable à un écart philosophique encore plus vaste et difficile à combler, Laurendeau acceptant bien plus facilement que le Canada français, voire le Canada dans son ensemble pussent se constituer de manière autonome en d'authentiques sujets politiques, libres de choisir leur propre destin. Le principe d'hétéronomie sur lequel Simard, en revanche, fondait ses arguments, le rôle directeur qu'il attribuait ainsi à la Providence dans le déroulement spécifique des affaires temporelles et de l'Histoire du monde, cela le tenait très clairement à l'écart de la modernité dont l'œuvre de Laurendeau était traversée. Le directeur de L'Action nationale, d'ailleurs, avait fait siennes les idées des penseurs personnalistes dont il avait fait la rencontre dans les milieux catholiques français lors d'un long voyage en Europe, quelques années plus tôt ${ }^{104}$. Plaidant dorénavant en faveur d'un catholicisme modernisé, progressiste et social, rejetant la superficialité de la pratique religieuse traditionnelle du Canada français et revendiquant la responsabilisation du laïcat devant l’Église et la société tout à la fois, Laurendeau avait déjà pris beaucoup de distance par rapport à plusieurs de ses convictions antérieures, y compris le « séparatisme » dont il avait été l'un des chefs de file, au début des années 1930, alors

103. Ibid., p. 354.

104. Pascale Ryan, Penser la nation. La Ligue d'action nationale, 1917-1960, Montréal, Leméac, 2006, 324 p. ; Yvan Lamonde, «André Laurendeau en Europe (1935-1937) : la recherche d'un nouvel ordre », Les Cahiers des Dix, n 61 (2007), p. 215-251. 
qu'il dirigeait les Jeune-Canada ${ }^{105}$. Cette évolution intellectuelle et philosophique, il en rendit compte directement au père Simard, d'ailleurs, dans un échange épistolaire qui eut lieu peu de temps après l'affrontement auquel s'étaient livrés les deux intellectuels par revues interposées ${ }^{106}$.

Simard tenait toutefois à ce que L'Action nationale publiât une réponse officielle à la dénonciation de Laurendeau, laquelle fut préparée par son collègue de l'Institut de philosophie de 1'Université d'Ottawa, Maurice Chagnon. Aussi condescendant envers Laurendeau que ce dernier avait été virulent envers Simard, Chagnon releva les nombreuses erreurs d'interprétation théologique qu'il croyait déceler dans son argumentaire, qu'il ramena, pour l'essentiel, à sa candeur, à son manque de profondeur intellectuelle et à l'intransigeance de son nationalisme ${ }^{107}$. L'article de Simard, celui qui avait suscité tant de controverse, fut republié peu de temps après dans un recueil de conférences initialement diffusées sur les ondes de Radio-Canada ${ }^{108}$. Intitulé Maux présents et foi chrétienne, l'ouvrage se voulait une étude du «problème du mal », dont Simard souligna abondamment que l'origine était bel et bien humaine et non divine ou providentielle, comme pour mettre un terme au débat et exiger de ses détracteurs qu'ils se taisent une fois pour toutes. La dernière partie du recueil promettait aussi d'identifier les « applications » de ses méditations théologiques au Canada, la guerre ayant déjà commencé à mettre à rude épreuve la « concorde » qu'il fallait au contraire préserver et cultiver entre les deux grandes nationalités qui composaient le peuple canadien. Canadiens français et Canadiens anglais, malgré

105. Sur le personnalisme et son influence au Canada français, voir E.-Martin Meunier et Jean-Philippe Warren, Sortir de la " Grande Noirceur ». L'horizon personnaliste de la Révolution tranquille, Sillery, Septentrion, 2002, 209 p. ; Michael Gauvreau, The Catholic Origins of Quebec's Quiet Revolution, 1931-1970, Montréal et Kingston, McGill-Queen's University Press, 2005, 501 p.

106. Denis Monière, "André Laurendeau, retour d'Europe », L'Action nationale, décembre 1983, p. 303-304.

107. Maurice Chagnon, «Défense et illustration du R. Père Georges Simard ", L'Action nationale, octobre 1940, p. 150-159.

108. Georges Simard, Maux présents et foi chrétienne, Ottawa et Montréal, Éditions de l'Université d'Ottawa et Éditions Beauchemin, 1940, 209 p. 
tout ce qui pouvait les séparer par ailleurs, possédaient à ses yeux un « fonds considérable d'identité », lequel s'était construit à la faveur des jeux d'alliance et de conquêtes qui avaient rapproché, historiquement, la France et 1'Angleterre ${ }^{109}$. La « concorde » devait se fonder sur 1' « union des volontés », laquelle reposait en revanche sur « l'unité de gouvernement ${ }^{110} »$, affirmation qui permit à Simard de professer son admiration pour les institutions britanniques, qui étaient aussi celles du Canada, dans une large mesure, et dont il estimait qu'elles auraient sans doute trouvé grâce aux yeux de saint Thomas :

C'est entendu, l'ancienne Rome, Carthage, même l'Angleterre depuis 1689 ont été conduites par une classe de riches et de puissants, une aristocratie dont le bloc solide comme le granit a résisté des siècles et des siècles aux coups les plus meurtriers de l'histoire. Dans le choc et le tumulte des forces contraires, chose singulière à observer, ces divers pays ont gardé plus d'équilibre que les peuples latins modernes ou les gouvernements issus de la Révolution. C'est un fait, si saint Thomas revenait de nos jours et qu'il cherchât [sic] chez les nations civilisées lesquelles répondent le plus fidèlement aux idées de sa politique, après réflexion il mentionnerait, je crois bien, l’Angleterre. On peut dire avec humour que l'Angleterre est un gouvernement aristocratique ayant pour cadre une monarchie apparente et une démocratie imaginaire, mais il n'empêche que dans l'art du gouvernement, des auteurs fort sérieux, même français, lui décernent la palme ${ }^{111}$.

109. Ibid., p. 173. L'argument préfigurait celui que développerait trois ans plus tard l'abbé Arthur Maheux. Au lendemain du plébiscite de 1942, qui avait exposé sans le moindre doute l'opposition diamétrale des deux grands groupes ethnolinguistiques sur la question litigieuse de la conscription militaire, l'historien bon-ententiste de l'Université Laval proposa même qu'on enseignât à tous les écoliers du Canada une version unique de l'histoire du pays afin de favoriser la consolidation d'un sentiment patriotique commun (voir Arthur Maheux, Pourquoi sommes-nous divisés? Montréal, Radio-Canada, 1943, 217 p.). L'ouvrage de Maheux attisa l'indignation de l'abbé Groulx, qui lui servit une cinglante riposte sous la forme d'une brochure intitulée Pourquoi nous sommes divisés (Montréal, Éditions de l'Action nationale, 1943, 42 p.).

110. Georges Simard, Maux présents et foi chrétienne, op. cit., 1940, p. 180.

111. Ibid., p. 187. 
La foi dans la supériorité des institutions britanniques était, bien entendu, l'un des thèmes de prédilection du loyalisme canadienfrançais. L'auteur reconnut toutefois qu'il manquait au Canada le « pouvoir de modération » du roi, ainsi que « le pouvoir de continuité qui [était] le propre d'un gouvernement aristocratique », mais une œuvre d'instruction et d'éducation reposant, encore une fois, sur de solides assises pouvant susciter l'adhésion de chacun à l'« idéal canadien » devait permettre, rassura-t-il ses lecteurs, de pallier ces lacunes. La réflexion sur la question du régime était somme toute peu développée dans la production intellectuelle du père Simard, ce qui ne l'empêcha pas, en revanche, d'être plus substantielle que chez plusieurs de ses contemporains, en particulier ceux du camp groulxiste qui imputaient sans trop d'ambiguïté le « mal » qui guettait les Canadiens français à des causes davantage spirituelles que politiques ou institutionnelles au sens strict ${ }^{112}$. Entre le chaos issu de la démocratie révolutionnaire et la stabilité que permettaient, en revanche, les institutions britanniques, le choix qui s'imposait aux Canadiens français, à ses yeux, ne souffrait d'aucune équivoque.

Posons maintenant une question délicate : le loyalisme de Simard, l'empressement qu'il mettait à justifier, en termes même théologiques, l'existence de l'Empire britannique et à y lier le destin du Canada, cela faisait-il de lui un impérialiste ? Rappelons que l'abbé Groulx, dans ses Mémoires, n'a pas hésité à répondre par l'affirmative. Était-il possible pour Simard d'être impérialiste tout en croyant, comme saint Augustin, que les empires étaient un « mal », absolument parlant, malgré toutes les nuances, voire les circonvolutions dont il pouvait entourer cette conviction ? Heureusement, notre oblat tâcha d'apporter lui-même une réponse à la question. L' « impérialisme politique », expliqua-t-il, alors que la guerre faisait toujours rage, était une doctrine qui installait une relation de sujétion et de soumission entre une « possession » et son « possesseur ». Seuls les « impérialistes vieux jeu » pou-

112. Michel Bock, «Le rapport des groulxistes au politique. Entre méfiance et tentation ", Vingtième siècle. Revue d'histoire, n 129, janvier-mars 2016, p. 27-42. 
vaient encore adhérer à cette idéologie, qui « ne se présent[ait] pas sérieusement à l'esprit d'un homme quelque peu versé en histoire, en philosophie et en théologie ${ }^{113} »$. Or il ne fallait pas écarter de sitôt le lien avec la Grande-Bretagne, s'empressa-t-il de souligner. Le Canada était désormais souverain, « au dire de plusieurs », de sorte que les hommes d'État canadiens, mus par des « aspirations » semblables, avaient pu choisir « de prendre part à la guerre actuelle à côté de l'Angleterre » sans nécessairement croire « faire œuvre d'impérialistes ${ }^{114}$. Au demeurant, il ne fallait pas être impérialiste pour considérer et apprécier la « superbe structure politique » qu'était l'Empire, ni pour admettre que «l'Empire britannique [avait] rendu certains services à l'Église ou qu'il [pouvait] être, à l'heure actuelle, une aide dans les mains de la Providence pour combattre le nazisme et le communisme $»^{115}$. Autrement dit, admirer l'Empire ne conduisait pas nécessairement à l'impérialisme. Il y avait là un pas que Simard n'était pas prêt à franchir : si son loyalisme ne faisait guère de doute, force est de constater que l'intensité de son « impérialisme », en revanche, paraissait moins élevée.

\section{Conclusion}

Pendant les quelque quinze dernières années de sa vie, le père Simard prendrait encore la plume à quelques reprises pour défendre ses idées, sans toutefois s'écarter de manière significative des thèses qu'il avait développées depuis le début des années $1930^{116}$. Si on a pu voir en lui tantôt un impérialiste, tantôt un bourrassiste $^{117}$, il appert que sa pensée, fuyante et en constante évolution, résiste aux catégorisations faciles. De groulxiste, ou de « char-

113. Georges Simard, « Notre credo national », RUO, 1941, p. 143.

114. Ibid., p. 144.

115. Ibid., p. 144.

116. Voir, notamment, Georges Simard, « Par[-]delà 1'Outaouais. À propos de culture canadienne-française », RUO, 1941, p. 265-267 ; «Une doctrine d'éducation nationale », RUO, 1943, p. 137-154, 269-273 ; " Pour une éducation catholique et canadienne-française », RuO, 1948, p. 413-421.

117. Jean Genest, « La querelle des nationalismes. Québec ou Ottawa », L'Action nationale, mai 1965, p. 879. 
leboisien » qu'il avait été au moment de son arrivée à Ottawa, le père Simard était devenu " bon-ententiste », puis loyaliste, sans toutefois véritablement pousser ses convictions idéologiques jusqu'à englober tout à fait l'impérialisme. Certains ont lié ce retournement de veste au revirement de fortune des partis libéral et conservateur au début des années 1930. Il nous semble, toutefois, qu'il est possible de faire une autre lecture du phénomène en le situant plus précisément dans son contexte politico-religieux. Le père Simard représente un cas, un beau cas, qui nous permet de prendre la mesure de la transformation qu'a connue le champ intellectuel de l'Ontario français et du Canada français pendant l'entre-deux-guerres, laquelle était surdéterminée, du moins pour certains, par le positionnement romain sur la question du nationalisme depuis les années 1910 (à commencer par la double intervention du Saint-Siège dans la crise du Règlement 17). Le débat sur le rapport entre les questions nationale et religieuse, qui conduirait l'Action catholique, à gauche des groulxistes, à se dépolitiser et à se dénationaliser pendant les années 1930, et qui conduirait à l'inverse une partie du mouvement nationaliste, cette fois à leur droite, à se radicaliser, en tâchant de se réconcilier avec le politique, ce débat, disons-nous, ne passa pas inaperçu dans la capitale fédérale, les intellectuels de l'Université d'Ottawa, pour peu que le parcours de Simard en soit un indicateur, y prenant part aussi. Esquissons un programme de recherche : si Simard est un cas, il faudra aussi l'opposer à d'autres cas, à la fois semblables et différents, afin de déterminer s'il a pu exister une manière " oblate » et " ottavienne » de débattre de la question nationale, politique et religieuse canadienne-française au $\mathrm{xx}^{\mathrm{e}}$ siècle. Là-dessus, parcourons une dernière fois quelques lignes du père Simard, qui expliqua avec une certaine candeur, en 1937, ce qui le motivait à combattre le « séparatisme» :

Ainsi, je serais fédéraliste ? La réponse n'offre pas d'importance dans un débat d'une si extrême gravité. Tout de même, après avoir vécu près de quarante ans dans l'Ontario et dans la Capitale du Canada, et après avoir suivi ou servi tant de nos 
causes sacrées, je m'estimerais coupable d'impertinence et de trahison si je déclarais dans un centre comme Ottawa que j'adhère à un courant d'idées qui, s'il allait réussir sur l'heure, entraînerait inévitablement la ruine des résultats obtenus par de nombreuses années d'efforts et de sacrifices communs ${ }^{118}$.

Quoi qu'il en soit, il paraît d'ores et déjà clair que la question religieuse offre à l'historien des idées une clé précieuse pour comprendre la transformation du champ intellectuel de l'Ontario français, ainsi que les origines du bilinguisme institutionnel au chapitre de son enseignement supérieur. Le catholicisme, dans lequel on a souvent vu le rempart des Franco-Ontariens contre l'hétéronomie institutionnelle et référentielle, a-t-il aussi pu en être le cheval de Troie, tout compte fait?

118. Georges Simard, « Principes et faits en histoire. État idéal et État canadien », RUO, 1937, p. 283. 